\title{
Network analysis of the left anterior descending coronary arteries in swim- trained rats by an in situ video microscopic technique
}

Marianna Török ${ }^{1 *+}$ D , Petra Merkely ${ }^{1 \dagger}$, Anna Monori-Kiss², Eszter Mária Horváth³ ${ }^{3}$ Réka Eszter Sziva ${ }^{1,3}$, Borbála Péterffy ${ }^{3}$, Attila Jósvai ${ }^{4}$, Alex Ali Sayour ${ }^{5}$, Attila Oláh ${ }^{5}$, Tamás Radovits ${ }^{5}$, Béla Merkely ${ }^{5}$, Nándor Ács ${ }^{1}$, György László Nádasy ${ }^{3}$ and Szabolcs Várbíró ${ }^{1}$

\begin{abstract}
Background: We aimed to identify sex differences in the network properties and to recognize the geometric alteration effects of long-term swim training in a rat model of exercise-induced left ventricular (LV) hypertrophy.

Methods: Thirty-eight Wistar rats were divided into four groups: male sedentary, female sedentary, male exercised and female exercised. After training sessions, LV morphology and function were checked by echocardiography. The geometry of the left coronary artery system was analysed on pressure-perfused, microsurgically prepared resistance artery networks using in situ video microscopy. All segments over $>80 \mu \mathrm{m}$ in diameter were studied using divided $50-\mu m$-long cylindrical ring units of the networks. Oxidative-nitrative (O-N) stress markers, adenosine $A_{2 A}$ and estrogen receptor (ER) were investigated by immunohistochemistry.

Results: The LV mass index, ejection fraction and fractional shortening significantly increased in exercised animals. We found substantial sex differences in the coronary network in the control groups and in the swim-trained animals. Ring frequency spectra were significantly different between male and female animals in both the sedentary and trained groups. The thickness of the wall was higher in males as a result of training. There were elevations in the populations of 200- and $400-\mu \mathrm{m}$ vessel units in males; the thinner ones developed farther and the thicker ones closer to the orifice. In females, a new population of 200- to 250- $\mu \mathrm{m}$ vessels appeared unusually close to the orifice.
\end{abstract}

Conclusions: Physical activity and LV hypertrophy were accompanied by a remodelling of coronary resistance artery network geometry that was different in both sexes.

Keywords: Ventricular hypertrophy, Exercise training, Resistance coronary arteries, Network, Sex differences, Video microscopic technique

\footnotetext{
* Correspondence: torok.marianna91@gmail.com;

torok.marianna@med.semmelweis-univ.hu

${ }^{\dagger}$ Marianna Török and Petra Merkely contributed equally to this work and are considered first authors

'Department of Obstetrics and Gynecology, Semmelweis University, Üllői u.

78/a, Budapest 1082, Hungary

Full list of author information is available at the end of the article
}

(c) The Author(s). 2021, corrected publication 2021. Open Access This article is licensed under a Creative Commons Attribution 4.0 International License, which permits use, sharing, adaptation, distribution and reproduction in any medium or format, as long as you give appropriate credit to the original author(s) and the source, provide a link to the Creative Commons licence, and indicate if changes were made. The images or other third party material in this article are included in the article's Creative Commons licence, unless indicated otherwise in a credit line to the material. If material is not included in the article's Creative Commons licence and your intended use is not permitted by statutory regulation or exceeds the permitted use, you will need to obtain permission directly from the copyright holder. To view a copy of this licence, visit http://creativecommons.org/ licenses/by/4.0/. The Creative Commons Public Domain Dedication waiver (http://creativecommons.org/publicdomain/zero/1. 0/) applies to the data made available in this article, unless otherwise stated in a credit line to the data. 


\section{Background}

The network geometry of the coronary arteries is very important in determining blood flow, but the methodical techniques for examining geometric properties are very difficult and expensive. Computed tomographic coronary angiography (CTCA) or coronary magnetic resonance (MR) angiography are possible examination methods [15]; 3D reconstruction is even possible [3]. However, only larger conduit arteries can be examined with these methods. There have been a limited number of publications in the literature studying alterations in small coronary artery networks [6-9]. Whole coronary artery network analysis (both conduit and resistance arteries) and comparisons with these methods are very complicated because each coronary network has a unique pattern. Previously, network remodeling of intramural coronary resistance arteries in aged rats and in hypertensive female rats was analysed with micropreparation and in situ video microscopic recording by Nádasy et al. [6, 7]. In aged rats and in rats with angiotensin infusioninduced hypertension, network rebuilding occurred that unfavourably changed hemodynamic resistance, including increased segmental tortuosity, parallel running branches, broken courses of larger branches, and multiple branchings and branch crossings $[6,7]$. In the present study, the questions of whether the network geometry adapted as a result of long-term exercise training and whether there are any differences in long-term exercise-induced coronary resistance artery network remodeling between the two sexes were addressed.

There is increasing evidence that an active lifestyle decreases the risk of coronary artery disease [10]. Such effects are induced by systemic metabolic factors [11], by reducing pathological alterations in large coronary vessels [12] and by improving ventricular microcirculation [13]. Furthermore, regular physical activity reduces obesity and helps keep the body weight at an optimal level [14]. Long-term, regular exercise induces a positive remodeling of the coronary resistance arteries themselves $[15,16]$. There are substantial differences in the structure and function of male and female coronary resistance arteries [17], and we can suppose that the effects of long-term exercise training on small coronary arteries and arterioles will be different in the two sexes. As a result of regular physical activity, the walls of large (conduit) coronary arteries and skeletal muscle arteries become thinner, and the lumens expand $[15,18]$, whereas the walls of the smaller resistance coronary arteries become thicker and more muscular [16]. Exercise training changes not only the morphology of the coronary arteries but also their function. The endothelial dilatation capacities of large and small coronary arteries are enhanced after exercise [18-20]. Endothelium-independent (adenosine) relaxation increases in conduit and large- resistance coronary arteries as a result of exercise training, but it has been found to be unaltered in smallresistance coronary arteries of trained rats [21]. Basal tone is higher in moderately trained coronary resistance arteries, which elevates the potential range of vasomotion during acute physical exercise. The balance between vasodilator and vasoconstrictor endogenous prostanoids favourably changes [16]. Substantial sex differences in endothelial relaxation have also been demonstrated with training in other vessels: the flow-mediated dilatation of the brachial artery increases in men but not in women after acute exercise [22-24]. Furthermore, the myogenic tone and the agonist-induced contraction (thromboxane agonist) of coronary arteries are greater only in female rats after strenuous physical exercise [25].

Oxidative stress reflects the imbalance between reactive oxygen radical production and adequate antioxidant protection. This is an unfavorable condition that can lead to cell and tissue damage and plays a role in aging; inflammatory processes; the development, initiation, and progression of cardiovascular, neurodegenerative, and cancerous lesions [26, 27]. The relationship between exercise and oxidative stress is extremely complex, depending on the type, intensity and length of the workout $[28,29]$. In addition to the many positive health effects of regular, moderate exercise, it also reduces oxidative stress. In contrast, acute training leads to increased oxidative stress, although this stimulus is required to activate endogenous antioxidant protection and thus indirectly to reduce chronic oxidative stress [30].

Oxidative and nitrative stress markers include 4hidroxy-2 nonenal (HNE), poly(ADP)-ribose (PAR), 3nitrotyrosine $(\mathrm{NT})$ and endothelial nitric oxide synthase (eNOS) [31-35]. The formation of HNE-protein-adducts is one of the accompanying processes in oxidative stress [31]. The level of PAR polymer can be considered as a molecular sensor of DNA damage, its level is significantly increased in diseases with oxidative and nitrative stress, such as inflammation or diabetes mellitus [32, 33]. 3-Nitrotyrosine is considered a relatively specific marker of peroxynitrite-mediated damage [34, 35]; levels are significantly elevated in many disease processes such as asthma, stroke or multiple sclerosis [35]. eNOS not only has antihypertensive, antithrombotic and antiatherosclerotic effects [36], but may be an important marker of oxidative stress. The superoxide anions react with the nitric oxide produced by eNOS to form peroxynitrite, which severely damages proteins, lipids and DNA, leading to cell damage and apoptosis [37].

Adenosine is an endogenous nucleoside which plays an important role in physiological and pathophysiological conditions within the coronary network. It acts primarily on the $A_{2 A}$ receptor (Ade $A_{2 A}-R$ ). In coronary heart disease, it is released from the heart muscle, endothelium, 
and immune cells during hypoxia, ischemia, or inflammation. $\mathrm{A}_{2 \mathrm{~A}}$ receptor activation improves coronary circulation and has an anti-inflammatory effect [38].

Vascular endothelial growth factor (VEGF) plays a key role in angiogenesis associated with regular physical activity. VEGF is responsible for coordinating among mechanical, chemical and transcriptional mediators as a result of exercise [39]. Previous studies have shown that there is an immediate increase in mRNA of VEGF upon exercise in skeletal and cardiac muscles [39]. The increase in VEGF mRNA levels is closely related to the function of hypoxia-induced factor 1-alpha (HIF-1- $\alpha$ ). During exercise, tissue oxygen levels decrease to an extent already sufficient for HIF-1- $\alpha$ activation, leading to VEGF activation [39]. The endothelial nitric oxide synthase (eNOS) plays a key role in the cardiovascular protective effect of exercise. Genetic deletion [40] or pharmacological inhibition [41] eliminate its cardioprotective effect. In the heart of the rodent, eNOS is located in $80 \%$ of the coronary endothelium [42].

Estrogen may play an important role in exerciseinduced remodeling. Of its two receptors ( $\alpha$ and $\beta$ ), $\beta$ receptor activation plays a role in angiogenesis in many tissues and improves endothelial dilatation [43, 44].

In the present study, we show how the intramural resistance coronary artery network running underneath the surface of the rat heart is altered after 12 weeks of swim training and what differences can be detected between males and females.

\section{Materials and methods}

\section{Ethical approval and animals}

Young adult, 50- to 54-day-old age-matched male ( $n=$ $18)$ and female $(n=20)$ Wistar rats were included in the coronary network preparation study. Rats were housed in standard cages at constant room temperature $(22 \pm 2$ ${ }^{\circ} \mathrm{C}$ ) and humidity with 12 -h light-dark cycles. They were supplied ad libitum with standard laboratory rat diet and with tap water. Experimental plans were approved by the Animal Care Committee of Semmelweis University and Hungarian authorities (Permission Number: PEI/ 001/2374-4/2015). Throughout the experiments, the regulations of the 'Guide for the Care and Use of Laboratory Animals' by the National Institutes of Health (NIH Publication No. 86-23, revised 1996.) and the EU Directive $2010 / 63 / \mathrm{EU}$ were followed.

\section{Chemicals}

Pentobarbital (Euthasol, CEVA Santé Animale, Libourne, France) was used for anaesthesia. For in vitro studies, we used a normal Krebs-Ringer solution (nKR), which consisted of the following (in mmol/l): $119 \mathrm{NaCl}, 4.7 \mathrm{KCl}$, $1.2 \mathrm{NaH}_{2} \mathrm{PO}_{4}, 1.17 \mathrm{MgSO}_{4}, 24 \mathrm{NaHCO}_{3}, 2.5 \mathrm{CaCl}_{2}, 5.5$ glucose and 0.0345 EDTA. Chemicals were purchased from Reanal (Budapest, Hungary).

\section{Experimental groups and swim training protocol}

After 7 days of acclimatization, animals were randomly divided into one of the following four experimental groups: male sedentary (MSed, $n=8$ ), male exercised (MEx, $n=$ 10), female sedentary (FSed, $n=10$ ) and female exercised (FEx, $n=10$ ). The numbers of animals for these groups were 8,10,10 and 10, respectively. Exercised male and female rats were subjected to a strenuous long-term swim training programme. After initial adaptation, both male and female rats swam for a total period of 12 weeks, for $200 \mathrm{~min} /$ day, 5 days a week as previously described [45]. Briefly, animals were placed in a water tank (with plain walls) divided into 6 lanes filled with tap water $\left(30-32{ }^{\circ} \mathrm{C}\right)$ at the same time of day in all training sessions. For adequate adaptation, the initial swimming duration was 15 min on the first day, and the duration of swimming was increased by 15 min every 2 days until reaching the maximal $200 \mathrm{~min} /$ day. Untrained control male and female Wistar rats were placed in the water tank for 5 min each day during the 12-week swim training programme.

\section{Echocardiography}

Echocardiography was performed at the end of the experimental period as described previously [46]. In brief, rats were anaesthetized with $1-2 \%$ isoflurane in $100 \%$ oxygen. Animals' body temperature was maintained at $37^{\circ} \mathrm{C}$ with a heating pad. The transthoracic echocardiography was conducted by using a $13-\mathrm{MHz}$ linear transducer (GE, Healthcare, Horten, Norway) attached to a Vividi Echocardiac Image Analysis System (GE, Healthcare, USA). Mid-papillary-level short-axis B-mode images were used to measure left ventricular (LV) anterior and posterior wall thicknesses (AWT and PWT, respectively) in diastole and LV end-diastolic and end-systolic diameters (LVEDD and LVESD, respectively). Images were analysed by blinded investigators with image analysis software (EchoPac v113, GE, Healthcare). The values of the three consecutive cycles were averaged and used for statistical analysis. The computed parameters were as follows: LV mass $=[[($ LVEDD + AWTd + PWTd $)^{3}-$ LVEDD $\left.\left.^{3}\right] \times 1.04\right] \times 0.8+0.14$ standardized for body mass, (LV mass index); fractional shortening (FS) = $($ LVEDD - LVESD)/LVEDD $\times 100]$. The ventricular volume values and ejection fraction $(\mathrm{EF})$ were computed according to the Teichholz method $((\mathrm{EF})(\%)=(\mathrm{LVEDV}-$ LVESV)/LVEDV $\times 100$ [47]).

\section{Micropreparation and in situ video microscopic recording of whole coronary networks}

At the end of the swim training programme, blood pressure was measured via the cannulation of the right 
carotid artery (Gould pressure heads) under pentobarbital anaesthesia (45 mg/kg body weight, intraperitoneal). Then, animals were perfused with $150 \mathrm{ml}$ of $\mathrm{nKR}$ solution to remove all blood from the vessels. The heart was removed to prepare the left anterior descending (LAD) coronary artery network. For the network preparation, we used a Wild M3Z preparation microscope as described previously [7, 48]. In brief, the heart was pinned down in a rubber-bottomed Petri dish and covered with cooled normal Krebs solution. By careful microsurgical preparation, the whole intramural network of the LAD was prepared and left in situ to maintain the original branching geometry. Larger branches of the LAD mostly run in the ventricular muscle tissue, parallel with the surface, a few hundred micrometres deep. Preparation followed the small arteries and large arterioles toward the periphery to vessels with diameters of approximately $80 \mu \mathrm{m}$. Then, the orifice was cannulated with plastic cannulas $(400 \mu \mathrm{m})$, and the network was perfused with Krebs-Ringer solution at close to in vivo pressures. Both the perfusate and superfusate nKR solutions were kept at constant temperatures of $37{ }^{\circ} \mathrm{C}$ and bubbled with a gas mixture of $5 \% \mathrm{CO}_{2}, 20 \% \mathrm{O}_{2}$ and $75 \%$ $\mathrm{N}_{2}$, which stabilized the $\mathrm{pH}$ at 7.4. After 2 min of equilibration, without any added vasoactive substance, the LAD network was recorded by a video microscope using low and high magnifications ( 8.58 and $1.47 \mu \mathrm{m} /$ pixel, respectively). The optical angle of the video microscope tube was kept perpendicular with the photographed surface, vertical, and bent approximately $30^{\circ}$ to the left, right, apically and toward the root of the heart to photograph the appropriate sections of the network. The analysis of the network pictures was performed off-line with the help of specific image-analyzing software (ImageJ, NIH, Bethesda, MA, USA). The length calibration was made with a micrometre etalon (Wild, Heerbrugg, Switzerland).

\section{Geometric analysis \\ High-magnification reconstruction of the network}

Using the low-magnification pictures, high-magnification pictures were selected with good visibility and perpendicular position of the parts of the network with the microscope tube axis. The picture of the whole network was then reconstructed in the form of a collage of highmagnification pictures. Further measurements were made on this reconstructed network, which contained all larger branches of the LAD stretched in the horizontal plane. Segments of the network were then numbered (Fig. 1).

\section{Analysis of bifurcations (branchings)}

All bifurcations (branchings) in the $>80-\mu \mathrm{m}$ range were identified (361 in the four groups) and were characterized by the inner diameters of the mother and daughter branches as well as by the angles of the axis of daughter branches with that of the mother branch.

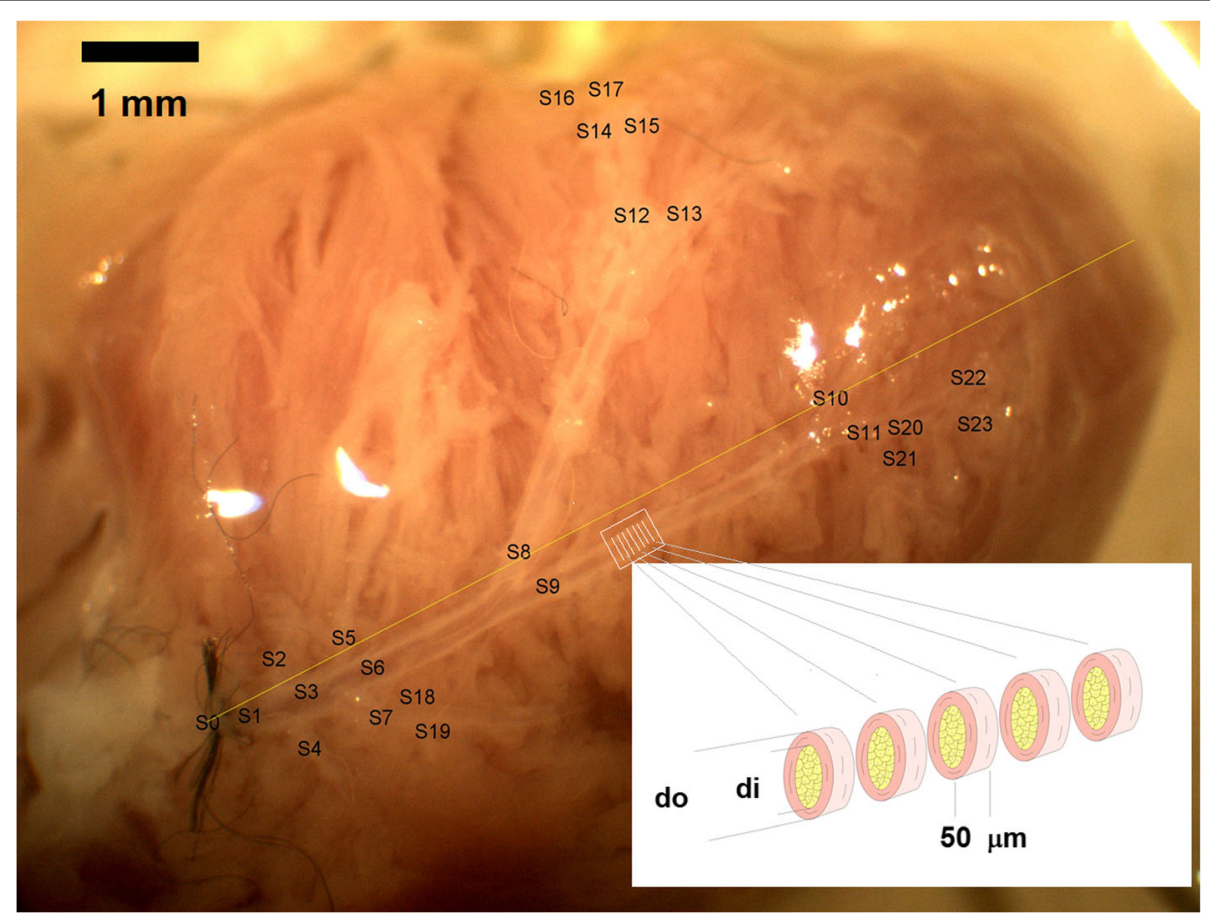

Fig. 1 Microprepared, pressure-perfused, video microscopy images of intramural coronary resistance artery network branches of the left coronary artery of an exercised male rat. Note the orifice-apex axis drawn and the numbering of segments. Scale bar, $1 \mathrm{~mm}$ 


\section{Vascular ring unit analysis}

The networks were divided (theoretically) into 50- $\mu \mathrm{m}$ long ring units. A Cartesian coordinate system was laid upon the high-magnification collage picture of the network. The $X$-axis was drawn between the lower contour of the orifice and the apex [7]. The $Y$-axis was drawn perpendicularly with it through the orifice, with positive values toward the left ventricle. The orifice was defined as the zero point. For each $50-\mu \mathrm{m}$-long ring unit, with several hundreds of them for each network, the outer and inner radii, wall thickness, $X$ and $Y$ coordinates for the ring centre, angle of axis with the $X$-axis, direct distance from the orifice and flow distance along the flow route from the orifice were computed. The overall number of ring units in the four groups, 38 animals, was 29 , 390.

\section{Mathematical analysis of alterations in network geometry}

Potential alterations in network geometry and sex differences were analysed as follows: Branchings were tested for the validity of Murray's law. According to the law, the sum of the cubes of the lumens of the daughter branches is equal to the cube of the lumen of the mother branch (Murray), which ensures identical shear rates induced by blood flow at the endothelium (Fig. 2). Characteristics of branching angles were tested on plots on which the angle of the axis of the daughter branch with the axis of the mother branch was plotted against the ratio of mother/daughter lumina. The value is $90^{\circ}$ where the daughter branch arises perpendicularly and 180 degrees if it continues the course of that of the mother branch (Fig. 3). Remodeling processes often alter lumen diameter/wall thickness ratios. Such plots are shown in Fig. 4. In previous works, we found it fruitful to construct histograms of the frequency of ring units in separate diameter ranges, which can reveal remodelling processes of resistance artery populations (Fig. 5). Such histograms yield even more detailed insight if twodimensional histograms are constructed-one dimension being the lumen diameter range, and the other being the distance through which the blood reaches the ring unit in question (computed from the orifice) [6, 7] (Fig. 6).

\section{Immunohistochemical examinations}

The whole heart was placed in $4 \%$ formaldehyde for fixation $(n=4-4)$. After dehydration, the tissues were embedded in paraffin and were cut into 5 - $\mu$ m-thick sections. Immunohistochemistry was performed against oxidative and nitrative stress markers, such as 4hydroxy-2-nonenal (HNE), poly(ADP)-ribose (PAR), 3nitrotyrosine (NT), endothelial nitric oxide synthase (eNOS) as well as for vascular endothelial growth factor

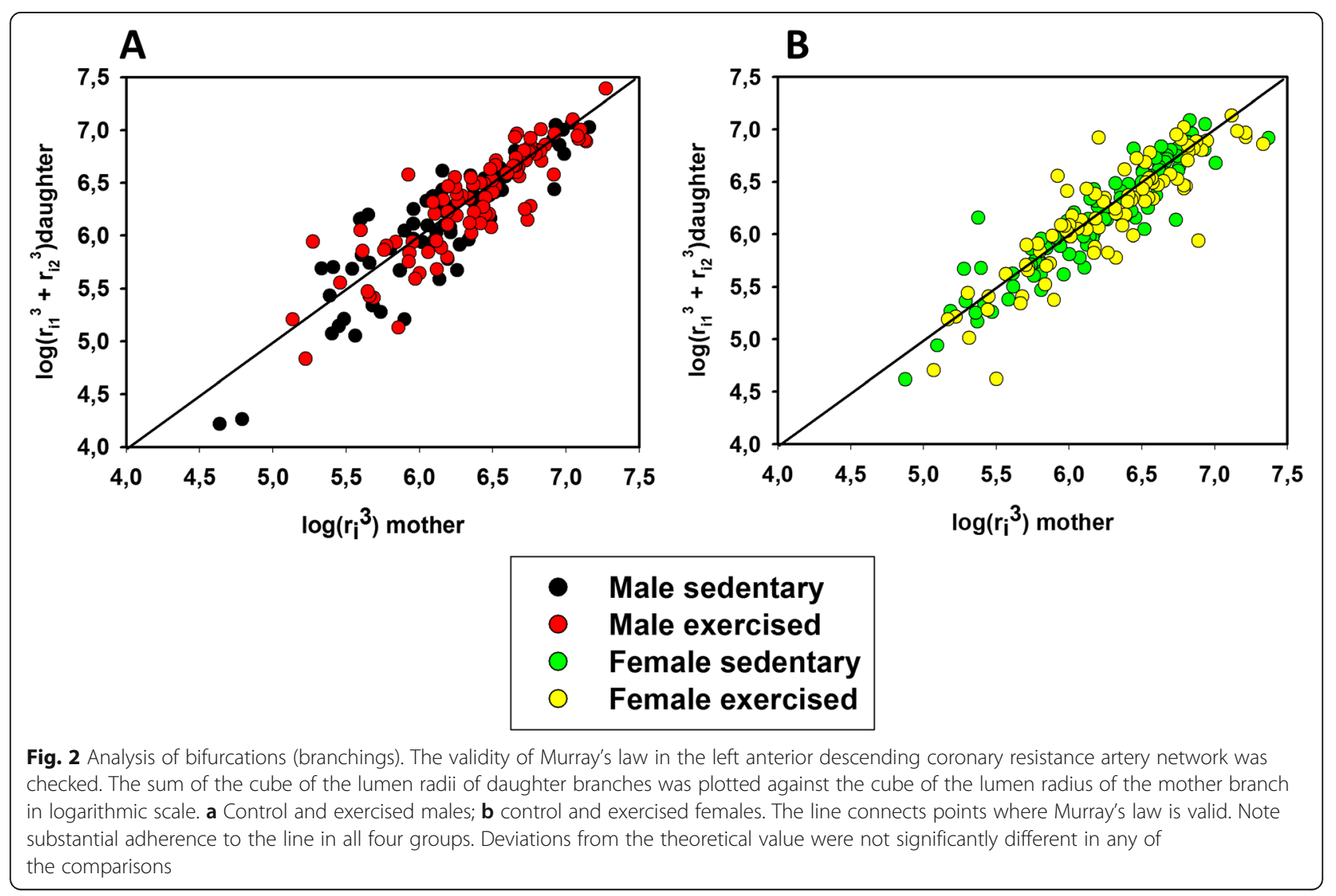




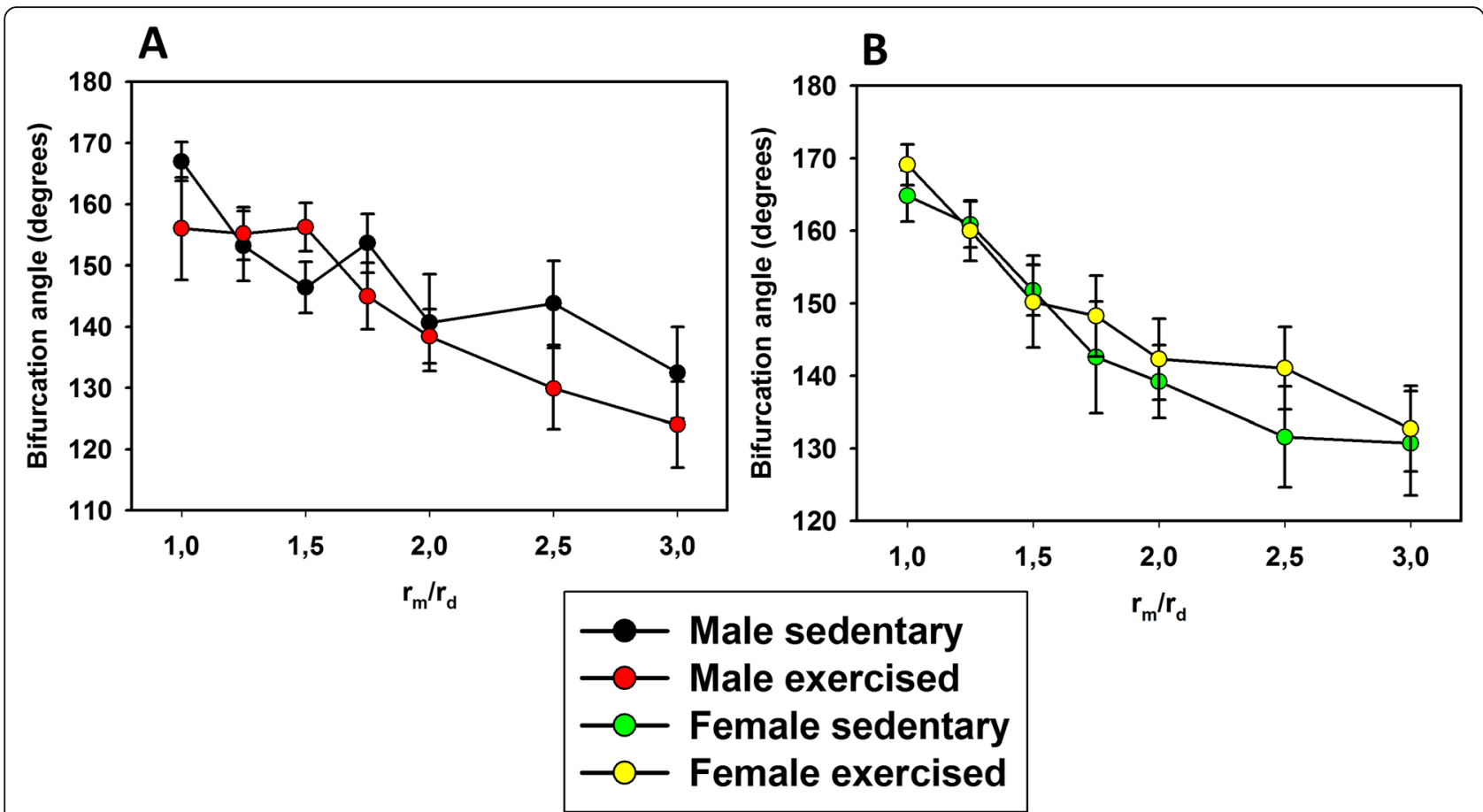

Fig. 3 Analysis of bifurcations (branchings). Angle of the axis of the daughter branch with the axis of the mother branch as a function of the ratio of lumen radii $\left(r_{\text {imother }} / r_{\text {idaughter }}\right)$. a Control and exercised males; $\mathbf{b}$ control and exercised females. Note that smaller daughter branches tend to deviate more from the course of the mother branch (angles closer to the perpendicular $90^{\circ}$ ), while larger daughter branches tend to follow the course of that of the mother branch (approximately $180^{\circ}$ ). Pearson correlations were significant in all four groups, with no significant differences between groups

receptor 1 (VEGFR-1), adenosine $A_{2 A}-R\left(\operatorname{Ade}_{2 A}-R\right)$ and estrogen receptor (ER). Polyclonal rabbit Anti-HNE (1: 500, Abcam, ab46545, Cambridge, MA, USA), Anti-NT (1:500, Abcam, ab42789, Cambridge, MA, USA), AntiVEGFR-1 (1:50, Novus Biologicals, VEGF-R1/Flit-1 Antibody NB100-92237, Centennial, CO, USA), Anti-ER $\alpha$ (1: 100, Merck/Sigma-Aldrich, \#06-935, Budapest, Hungary) and monoclonal mouse Anti-PAR (1:1000, Tulip Biolabs., Cat. \#1020, Landsdale, PA, USA), Anti-eNOS (1: 50, Abcam, ab76198, Cambridge, MA, USA) and AntiAdeA $_{2 A}-\mathrm{R}$ (1:50, Santa Cruz Biotechnology INC, 7F6G5-A2, sc-32261, Dallas, TX, USA) antibodies were applied. Secondary labeling was achieved by using horseradish-peroxidase (HRP)-labeled horse anti-rabbit or anti-mouse IgG polymer detection kit (Vector Laboratories, MP-7401, MP-7402, Burliname, CA, USA, 30 $\mathrm{min})$. Visualization of specific labeling with browncolored 3-3'-diamino-benzidine (DAB) peroxidase HRP substrate kit (Vector Laboratories, SK-4100, Burlingame, CA, USA) diaminobenzidine (DAB) as colored substrate and hematoxylin counterstaining was achieved by bluecolored hematoxylin QS nucleus stain (Vector Laboratories, H-3404-100, Burlingame, CA, USA). Microscopic images of immunostained tissue sections were taken by microscope-coupled videocamera (Nikon Eclipse NI NISS, 933584 with Nikon DS-Ri2 camera and NIS
Elements BR image software, Nikon Corporation, Japan). Non-calibrated optical density and staining intensity of specific staining was measured by Image software $(\mathrm{NIH}$, Bethesda, MA, USA).

\section{Statistical evaluation}

For statistical analysis, SPSS Sigma Stat software and Excel functions were used. All data are presented as the mean \pm SEM. The normal distribution was checked with the Shapiro-Wilk test. Two-way analysis of variance (ANOVA) was used with the post hoc Tukey test for paired comparisons, and the level of significance was set at $p<0.05$. Ring unit diameter distribution histograms of pooled data were compared with the $\chi^{2}$ test.

\section{Results}

Physiological alterations

As a result of the swim training programme, body weight was significantly reduced in male animals compared to control animals despite ad libitum feeding (Table 1). Body weights significantly differed between the male and female groups in both control and exercised animals (Table 1). The calculated LV mass index determined by echocardiography indicated cardiac hypertrophy in both exercised groups compared with control animals (Table 1). The LV mass index was 


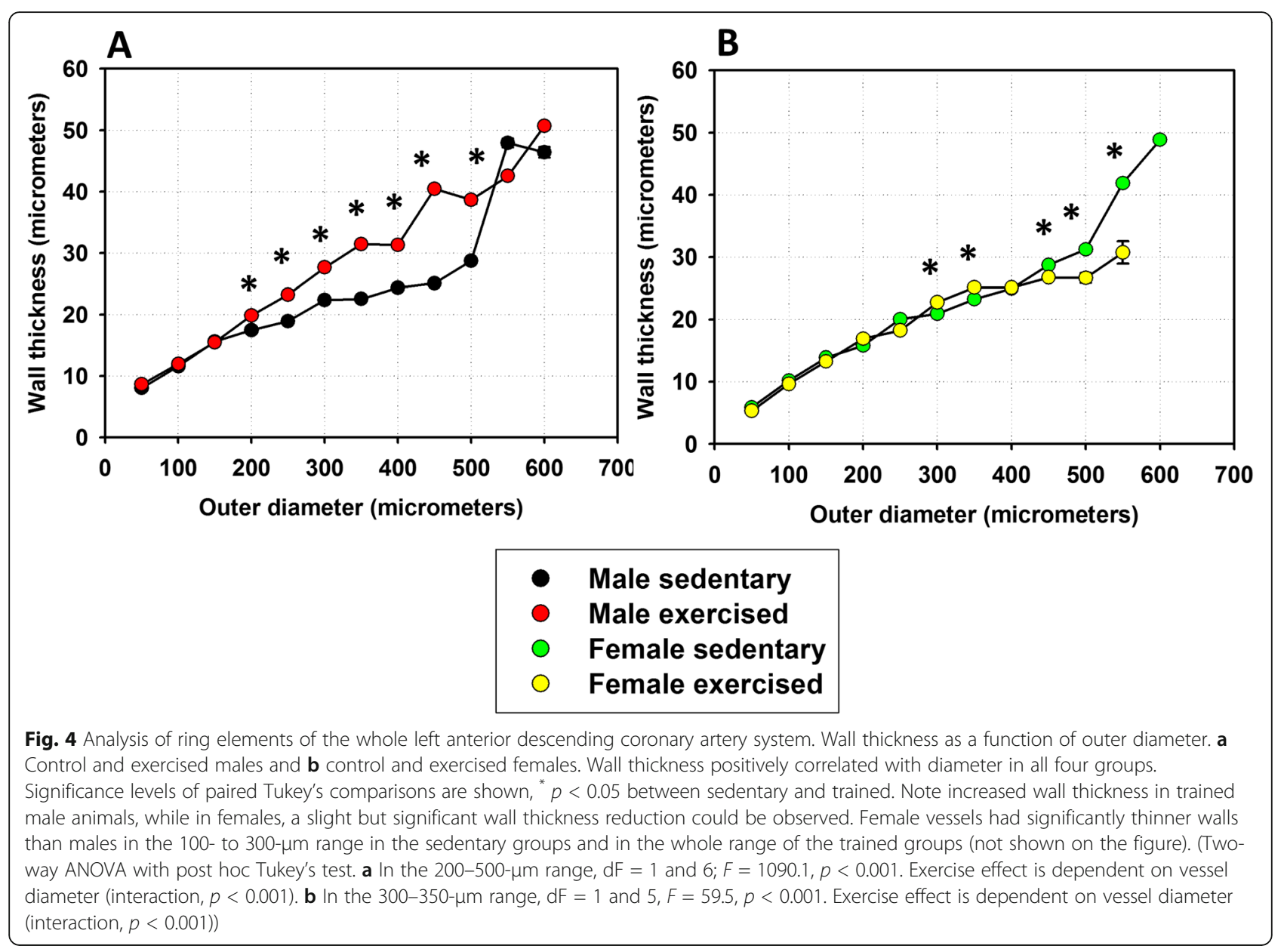

higher in female rats than in males in both the control and exercised groups, and female sex was associated with greater relative heart hypertrophy (Table 1). The systolic function of the hypertrophied heart (determined by the ejection fraction and fractional shortening) was significantly increased in exercised rats compared with sedentary animals in both the male and female groups (Table 1). The EF and FS were greater in female animals than in male rats in control groups, whereas they were not different between the trained groups (Table 1). The mean arterial pressure did not differ between groups (Table 1).

\section{Bifurcations (branchings)}

Lumen diameters of bifurcation adhered fairly well to Murray's law: the sum of the cubes of the lumen radii of the daughter branches was close to the cube of the mother branch. Deviations from theoretical values did not differ in the four groups in any of the comparisons (Fig. 2). In a similar manner, branching angles (defined as the angle between the axis of the mother branch and that of the daughter branch) increased with increasing lumen of the daughter branch. Negative correlations between the angles of axes and the ratios of diameters $\left(r_{m} / r_{d}\right)$ were equally characteristic for the four groups (Fig. 3).

\section{Ring unit analysis}

There were positive correlations of wall thickness with outer diameter in all four groups (Fig. 4). There was a significant elevation of wall thickness of the resistance arteries in the case of exercised male animals, while in females, a statistically significant reduction in wall thickness occurred in the larger arteries (Fig. 4). Females had slightly but significantly thinner walls than males in the sedentary state, but in exercised animals, female coronary vessels were significantly and massively thinner than those of males in the whole diameter range (not shown directly on the figure).

Ring frequency histograms (number of $50-\mu \mathrm{m}$ ring units, pooled for 10 animals) were significantly different between trained and sedentary animals in both sexes ( $p$ $<0.01$ with the $X^{2}$ probe, Fig. 5). In swim-trained males, the number of $400-\mu \mathrm{m}$ rings almost doubled, and there was a substantial elevation in the number of ring units also in the $200-\mu \mathrm{m}$ range compared with sedentary ones 


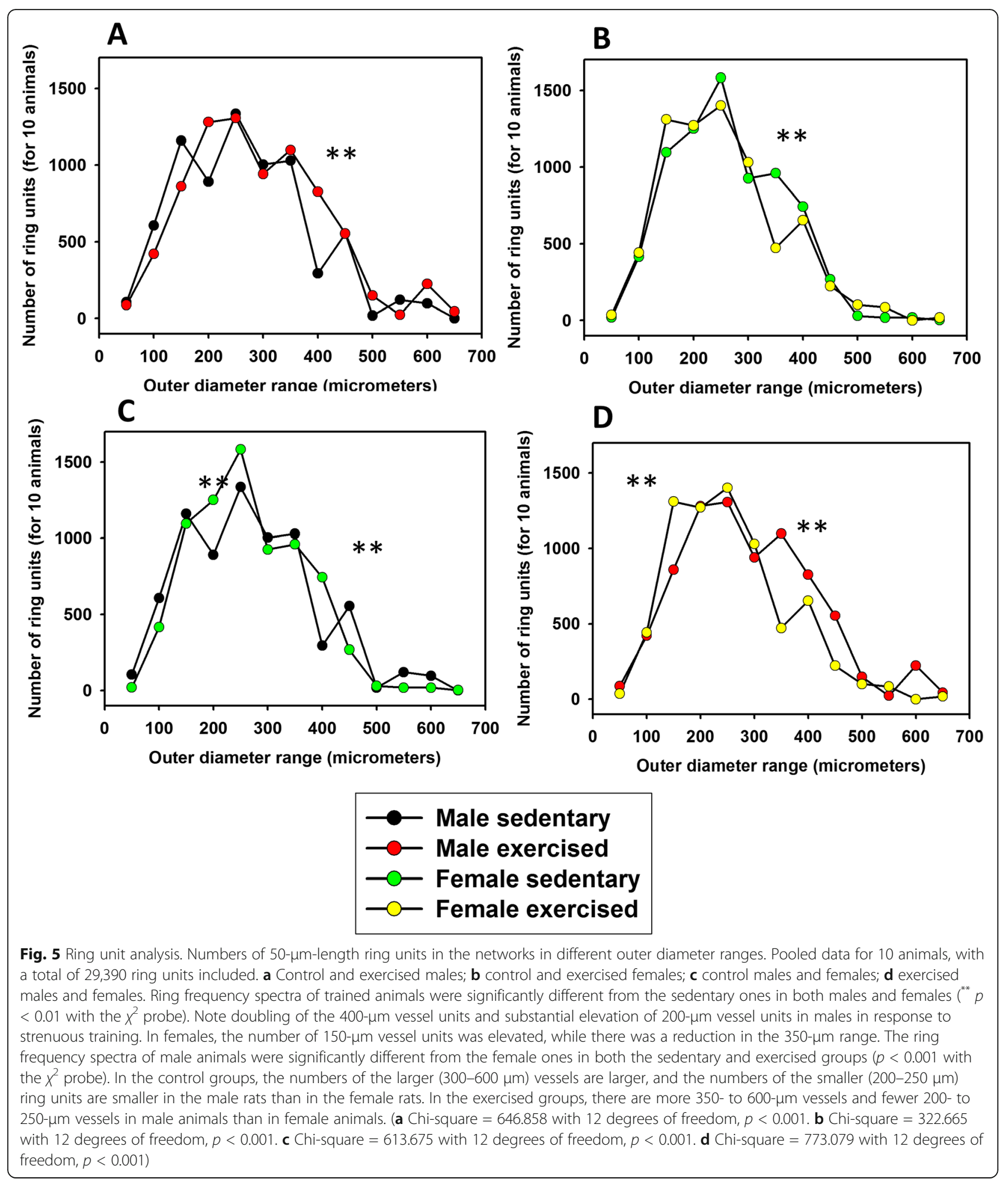

(Fig. 5a). In the case of females, the number of $150-\mu \mathrm{m}$ rings increased, while there was a reduction in the number of 350- $\mu \mathrm{m}$ units (Fig. $5 \mathrm{~b}$ ). The numbers of ring units did not differ in the four groups $(718 \pm 68,780 \pm 47$, $730 \pm 45$ and $705 \pm 30$ ring unit elements per heart for the MSed, MEx, FSed and FEx groups, respectively, n.s.). Ring frequency spectra were significantly different between male and female animals in both the sedentary and trained groups ( $p<0.01$ with the $\chi^{2}$ probe). Sedentary male networks had less abundant 200- to 250- and 


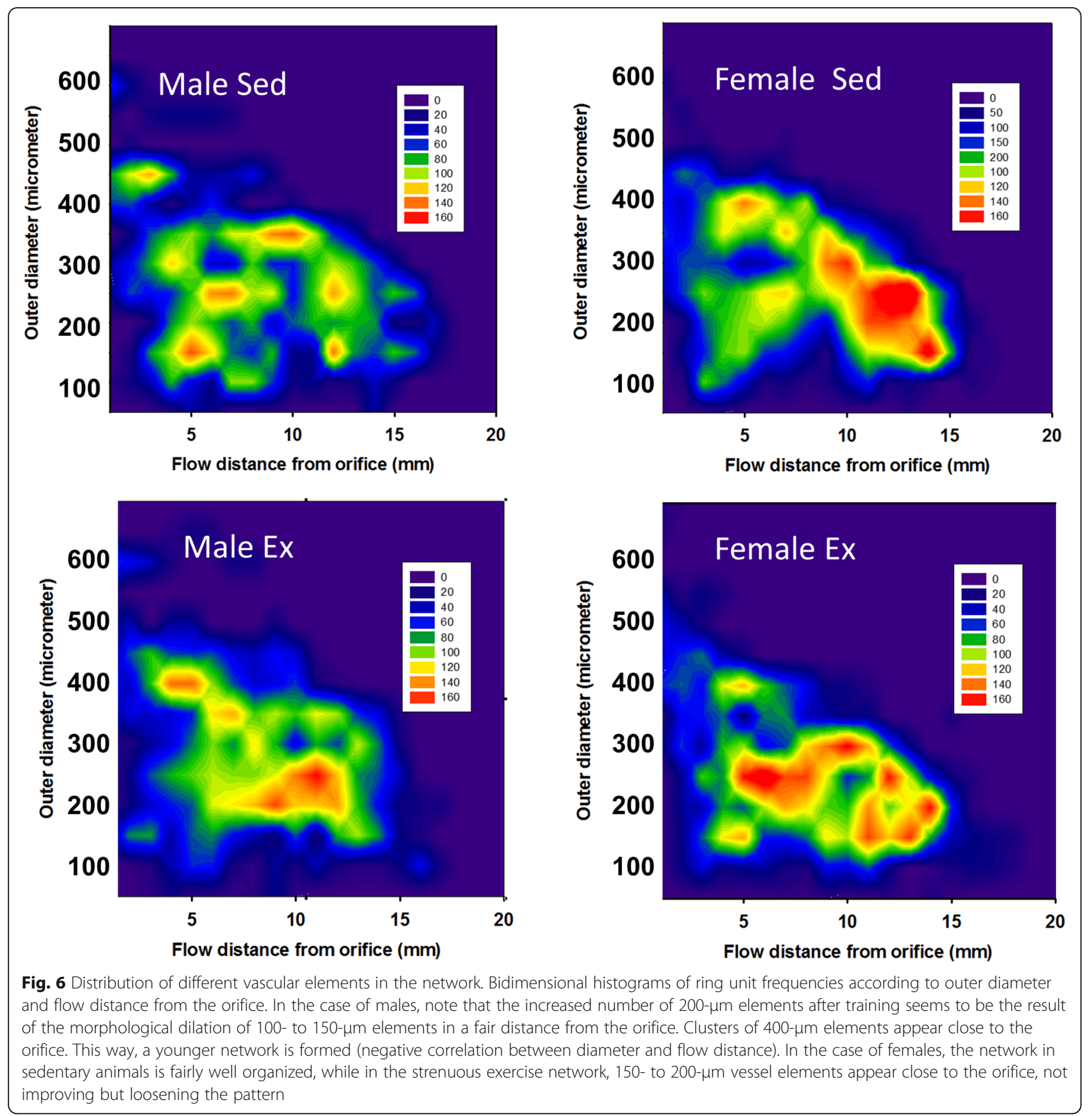

400- $\mu \mathrm{m}$ vascular units and more abundant 350- and > 500- $\mu \mathrm{m}$ units (Fig. 5c). Trained males had more abundant 350 - to $450-\mu \mathrm{m}$ units and less abundant $150-\mu \mathrm{m}$ diameter elements than corresponding trained females (Fig. 5d).

\section{Network distribution}

The next question was at what points of the network these characteristic differences in the frequency of vascular units appear. To answer this question, twodimensional ring unit frequency histograms were constructed, with one axis showing the outer diameter and the other showing the distance from the orifice following the route of blood flow with the number of units colour-coded (Fig. 6). Figure 6a and c demonstrate that the elevation of the number of thicker $400-\mu \mathrm{m}$ units occurred at the 'right' place, close $(3-5 \mathrm{~mm})$ to the orifice, while population extension of $200-\mu \mathrm{m}$ units occurred again where it was advantageous, at an 8- to $13-\mathrm{mm}$ distance from the orifice. For females in the sedentary state, a cluster of 150 - to $350-\mu \mathrm{m}$ units at a distance of $10-15$ $\mathrm{mm}$ is characteristic with the appearance of a new 150- 
Table 1 Basic characteristics and hemodynamic parameters in the study groups

\begin{tabular}{|c|c|c|c|c|c|}
\hline & MSed & MEx & FSed & FEx & $p_{i}$ \\
\hline BW, g & $487 \pm 11$ & $424 \pm 9^{*}$ & $287 \pm 4^{*}$ & $286 \pm 4^{\S}$ & $<0.001$ \\
\hline LV mass index, g/kg & $2.36 \pm 0.08$ & $3.05 \pm 0.08^{*}$ & $3.07 \pm 0.08^{*}$ & $3.64 \pm 0.10^{\# \S}$ & 0.471 \\
\hline$E F, \%$ & $73 \pm 1.0$ & $81 \pm 1.2^{*}$ & $79 \pm 0.8^{*}$ & $82 \pm 0.9^{\#}$ & 0.017 \\
\hline $\mathrm{FS}, \%$ & $44 \pm 0.9$ & $52 \pm 1.3^{*}$ & $49 \pm 0.8^{*}$ & $52 \pm 1.1^{\#}$ & 0.035 \\
\hline MAP, mmHg & $124 \pm 9$ & $123 \pm 8$ & $105 \pm 7$ & $110 \pm 5$ & 0.087 \\
\hline
\end{tabular}

$B W$ body weight at the end of the training program. $\left(F_{\text {training }}=15.193, F_{\text {sex }}=627.244, F_{\text {int }}=13.216, \mathrm{df}_{\text {training }}=1, \mathrm{df}_{\mathrm{sex}}=1, \mathrm{df}_{\text {int }}=1, P_{\text {training }}<0.001, P_{\mathrm{sex}}<0.001\right.$ and $\left.P_{\text {int }}<0.001\right)$; LV mass index, left ventricular mass standardized for body mass. $\left(F_{\text {training }}=64.55, F_{\text {sex }}=70.00, F_{\text {int }}=0.53, \mathrm{df}_{\text {training }}=1, \mathrm{df}_{\text {sex }}=1, \mathrm{df}_{\text {int }}=1, P_{\text {training }}\right.$ $<0.001, P_{\text {sex }}<0.001$ and $\left.P_{\text {int }}=0.47\right) ; E F$ ejection fraction. $\left(F_{\text {training }}=29.44, F_{\text {sex }}=10.36, F_{\text {int }}=6.26, \mathrm{df}_{\text {training }}=1, \mathrm{df}_{\text {sex }}=1, \mathrm{df}_{\text {int }}=1, P_{\text {training }}<0.001, P_{\text {sex }}=0.003\right.$ and $\left.P_{\text {int }}=0.02\right) ; F S$ fractional shortening. $\left(F_{\text {training }}=28.33, F_{\text {sex }}=6.43, F_{\text {int }}=4.82, \mathrm{df}_{\text {training }}=1, \mathrm{df}_{\text {sex }}=1, \mathrm{df}_{\text {int }}=1, P_{\text {training }}<0.001, P_{\text {sex }}=0.02\right.$ and $\left.P_{\text {int }}=0.04\right) ; M A P$ mean arterial pressure. $\left(F_{\text {training }}=0.008, F_{\text {sex }}=5.995, F_{\text {int }}=0.02, \mathrm{df}_{\text {training }}=1, \mathrm{df}_{\text {sex }}=1, \mathrm{df}_{\text {int }}=1, P_{\text {training }}=0.93, P_{\text {sex }}=0.019\right.$ and $\left.P_{\text {int }}=0.865\right)$

${ }^{*} p<0.05$ vs. MSed, $\S p<0.05$ vs. MEx, \# $p<0.05$ vs. FSed

to $250-\mu \mathrm{m}$ cluster at a close flow distance $(5-8 \mathrm{~mm})$ from the orifice after exercise (Fig. $6 \mathrm{~b}$ and d).

In the present study, we show how the intramural resistance coronary artery network running underneath the surface of the rat heart is altered after 12 weeks of swim training and what differences can be detected between males and females.

\section{Immunohistochemical examinations}

In the performed immunohistochemical studies measuring oxidative and nitrative stress (HNE, PAR, NT and eNOS markers) we did not find a significant difference between the trained and control groups, nor was there any gender difference in these markers (Fig. 7). Furthermore, no differences were found in the staining of VEGF R-1 receptors (Fig. 7).

Adenosine $\mathrm{A}_{2 \mathrm{~A}}$ receptor intensity was significantly decreased in males during exercise compared with the control group. Furthermore, the AdeA $_{2 \mathrm{~A}}$ receptor intensity of trained males was significantly lower even compared to female swimmers. In females, there was no change in Ade $_{2 \mathrm{~A}}$ receptor expression upon exercise (Fig. 8).

Estrogen receptor intensity was significantly decreased in trained males compared with their control group (Fig. 9). It is possible that the estrogen receptor plays a role not only in sex differences in myocardial hypertrophy $[49,50]$ but also in sex differences in vascular adaptation.

\section{Discussion}

In the present study, we first provide a reliable characterization of coronary resistance artery network remodeling in a rodent model of strenuous endurance training in which we applied an in situ micropreparation perfusion technique $[7,48]$. In addition, we described the differences between males and females in both the sedentary and the trained states. Our results may be due to altered expression of estrogen receptor (ER) and Ade $_{2 \mathrm{~A}}$ receptor.

\section{Physiological parameters}

Numerous animal and human studies investigated the physiological left ventricular hypertrophy induced by exercise training [50-52]. In agreement with most of the studies in rodents $[45,49,50]$, an increased relative LV mass (LV mass index) and systolic function (EF and FS) were observed in both male and female rats after our 12-week swim training programme. These alterations are a consequence of hypertrophy of ventricular myocytes [45]. Similar to our findings, Oláh et al. found that the body weight decreased only in the male exercised groups, whereas it did not change in the females [50]. Despite the left ventricular hypertrophy, the mean arterial pressure did not differ between the groups, which also illustrates the physiological nature of athletes' hearts.

Female animals had lower body weights in both the sedentary and exercised groups, similar to earlier publications in rodents and humans $[49,53]$. The LV mass index raised more in female animals than in males, in accordance with earlier studies $[49,50,54,55]$. Estrogen receptor type beta might be responsible for this difference [49]. Furthermore, Oláh et al. found that the ERK1/ 2, S6 and mTOR activation levels differed in the hearts of swimming female and male rats [50]. In our case, the LV mass index also differed between the two sexes in the sedentary state, with females having higher values. Despite the sex differences in LV index, no sex differences could be identified regarding systolic function (FS and $\mathrm{EF}$ ) in the exercised groups in our study.

\section{Coronary bifurcations (branchings)}

No significant differences in the bifurcation geometry could be identified between either the sedentary and trained groups or the sexes. All four groups adhered fairly well to Murray's law [56], which holds that the sum of the cubes of lumen radii of daughter branches should be equal to the cube of the lumen diameter of the mother branch (Fig. 2), ensuring that the stabilization of endothelial shear was effective in 


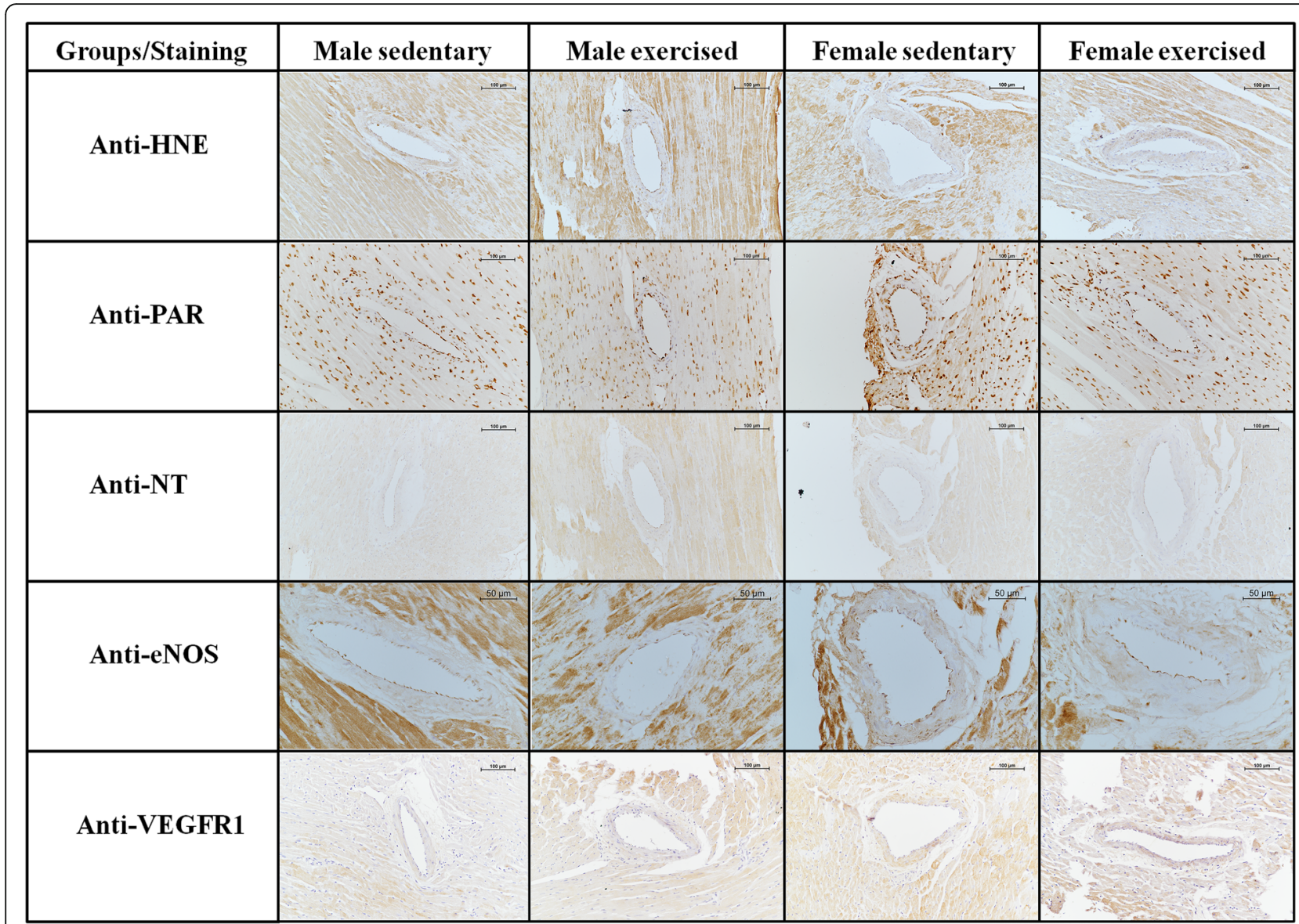

Fig. 7 Representative photos of 4-hydroxy-2-nonenal (HNE), poly(ADP)-ribose (PAR), 3-nitrotyrosine (NT), endothelial nitric oxide synthase (eNOS) and vascular growth factor receptor 1 (VEGFR-1) immunohistochemistry sections of control and exercised male and female coronary segments. Scale bar 50 or $100 \mu \mathrm{m}$. (Two-way ANOVA with post hoc Tukey's test. Anti-HNE, $F_{\text {training }}=0.375, F_{\text {sex }}=0.00135, F_{\text {int }}=0.000644, \mathrm{df}_{\text {training }}=1, \mathrm{df}_{\text {sex }}$ $=1, \mathrm{df}_{\text {int }}=1, P_{\text {training }}=0.553, P_{\text {sex }}=0.971$ and $P_{\text {int }}=0.98 ;$ Anti-PAR, $F_{\text {training }}=0.0136, F_{\text {sex }}=5.128, F_{\text {int }}=0.00267, \mathrm{df}_{\text {training }}=1, \mathrm{df}_{\text {sex }}=1, \mathrm{df}_{\text {int }}=1$, $P_{\text {training }}=0.909, P_{\text {sex }}=0.04$ and $P_{\text {int }}=0.873$; Anti-NT, $F_{\text {training }}=2.849, F_{\text {sex }}=0.0874, F_{\text {int }}=0.000248, \mathrm{df}_{\text {training }}=1, \mathrm{df}$ sex $=1, \mathrm{df}_{\text {int }}=1, P_{\text {training }}=0.114$, $P_{\text {sex }}=0.772$ and $P_{\text {int }}=0.988$; Anti-eNOS, $F_{\text {training }}=1.398, F_{\text {sex }}=0.785, F_{\text {int }}=0.029, \mathrm{df}_{\text {training }}=1, \mathrm{df}_{\text {sex }}=1, \mathrm{df}$ int $=1, P_{\text {training }}=0.264, P_{\text {sex }}=0.396$ and $P_{\text {int }}=0.868$; Anti-VEGFR-1, $F_{\text {training }}=1.99, F_{\text {sex }}=0.00448, F_{\text {int }}=0.118, \mathrm{df}_{\text {training }}=1, \mathrm{df}_{\text {sex }}=1, \mathrm{df}_{\text {int }}=1, P_{\text {training }}=0.18, P_{\text {sex }}=0.948$ and $P_{\text {int }}$ $=0.737$

coronary networks formed during the sedentary and trained states in both sexes. The validity of Murray's law was proven in coronary networks of aged rats [7] and in female rats made hypertensive by the chronic infusion of angiotensin II [6]. In all four groups, we found a fairly negative correlation between mother and daughter lumen ratios and angles of the daughter branch with the axis of the mother branch: while larger branches tended to follow the course of the mother branch, smaller branches deviated from it more (Fig. 3). Despite substantial left ventricular mass elevation, no branching deformities developed, similar to those found in aged [7] and in hypertensive [6] networks.

\section{Wall thickness}

As described above, whole networks were (theoretically) divided into 50- $\mu \mathrm{m}$ ring units, with 29,390 such "ring" units for the 38 animals. Fig. 4a demonstrates that as an effect of training, wall thickness significantly increased in the 200- to $500-\mu \mathrm{m}$ outer diameter range in males. We think that increased muscularity ensured increased range of vasomotion (between fully contracted and fully relaxed states), as has been observed in an earlier publication from our laboratory [25] with pressure arteriography for rat coronary arteriole segments in the $200-\mu \mathrm{m}$ range. There was some sex significance in this respect: training-induced wall thickening was moderate in female (300-350 $\mu \mathrm{m})$ vessels, and there was a characteristic thinning of the wall at the largest branches in this sex (Fig. 4b). There was no consensus in the literature as to the effect of training on coronary artery wall thickness: different parts of the circulation may be affected in a different manner $[16,21,57,58]$. 


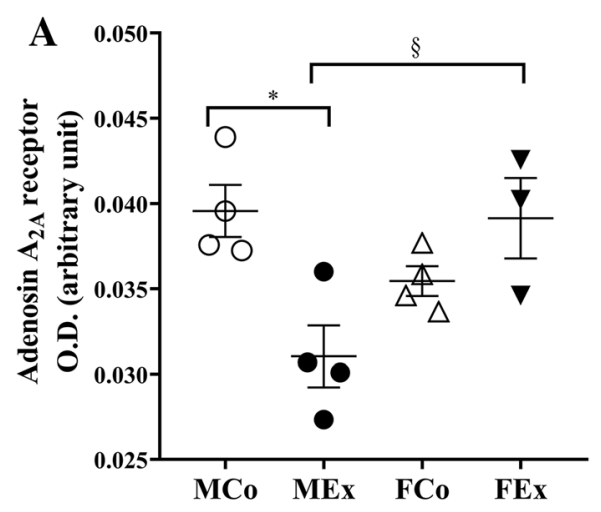

Fig. 8 Results of Adenosine $A_{2 A}$ receptor $\left(A d e A_{2 A}-R\right)$ immunohistochemical staining. a Ade $A_{2 A}-R$ optical density $(n=4-4-$ 4-3); $\boldsymbol{b}$ representative images of $A_{d e} A_{2 A}-R$ stained arteriole segments from MSed, MEx, FSed and FEx groups. Scale bar, $100 \mu \mathrm{m}$. Two-way ANOVA with post hoc Tukey's test. $\left(F_{\text {training }}=2.166, F_{\text {sex }}=\right.$ $1.465, F_{\text {int }}=13.779, \mathrm{df}_{\text {training }}=1, \mathrm{df}_{\text {sex }}=1, \mathrm{df}_{\text {int }}=1, P_{\text {training }}=0.169$, $P_{\text {sex }}=0.251$ and $P_{\text {int }}=0.003$ )

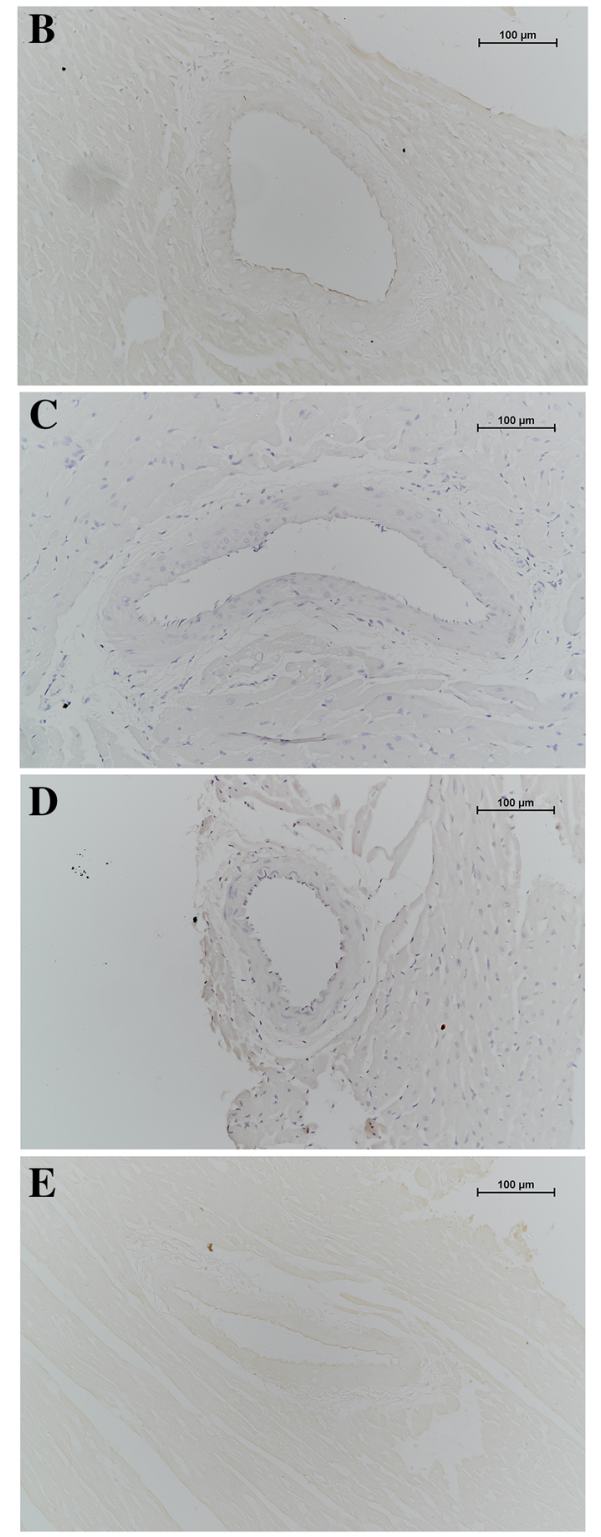

\section{Frequency of ring units building up the network}

Exercise-induced remodeling of the coronary resistance artery system can be spotted on the frequency diagrams of the ring units forming the whole network. In males, the number of 400- $\mu \mathrm{m}$ units almost doubled, and there was also a substantial elevation in the $200-\mu \mathrm{m}$ range (Fig. 5a). A similar alteration could be observed in females, but in the $150-\mu \mathrm{m}$ diameter range. However, in females, the 350- $\mu \mathrm{m}$ units substantially reduced in their number (Fig. 5b). As there was no alteration in the ring elements themselves, we have good reason to think that morphological dilation of earlier existing thinner vessels occurred. This result is not surprising because the elevated myocardial mass requires increased perfusion, which can be provided by a remodelled coronary circulation [59]. As a result of endurance exercise, the cardiac performance improves in healthy subjects, and the tolerance for ischaemia and reperfusion injury increases even in patients with LV dysfunction [60-62]. The decreased risk of ischemic heart disease might be due to increased capillary density and neo-angiogenesis in cardiac mass as a result of exercise $[39,63]$. Such events could have occurred in our case also, but these smaller resistance vessels penetrating the ventricular wall perpendicularly were outside the scope of our video microscopic study.

\section{Statistical geometry of the sedentary and exercised networks}

Despite the above-mentioned limitations, our technique yields a further possibility to pinpoint at what points of the network these remodeling processes have taken place. An analysis of the two-dimensional flow distancediameter ring unit frequency plots shows that in males, the elevation of 400- and 200- $\mu$ m units occurred at just the right place: very close-at $2 \mathrm{~mm}$ from the orifice for the thicker, $400-\mu \mathrm{m}$ vessels, and farther from the orifice $(8-12 \mathrm{~mm}$ ) for the $200-\mu \mathrm{m}$ ones (Fig. 6a and c). As a result, the exercised network became younger [7] and healthier [6]. There was a clear, hemodynamically advantageous tendency: thicker vessels were closer and thinner ones were farther from the orifice. We can observe a substantially different situation in females: in their case, the sedentary pattern seems to be the more coherent (thinner vessels being farther from the orifice-see the oblique line dominating the diagram of Fig. 6b). In the network developed under the effect of strenuous 


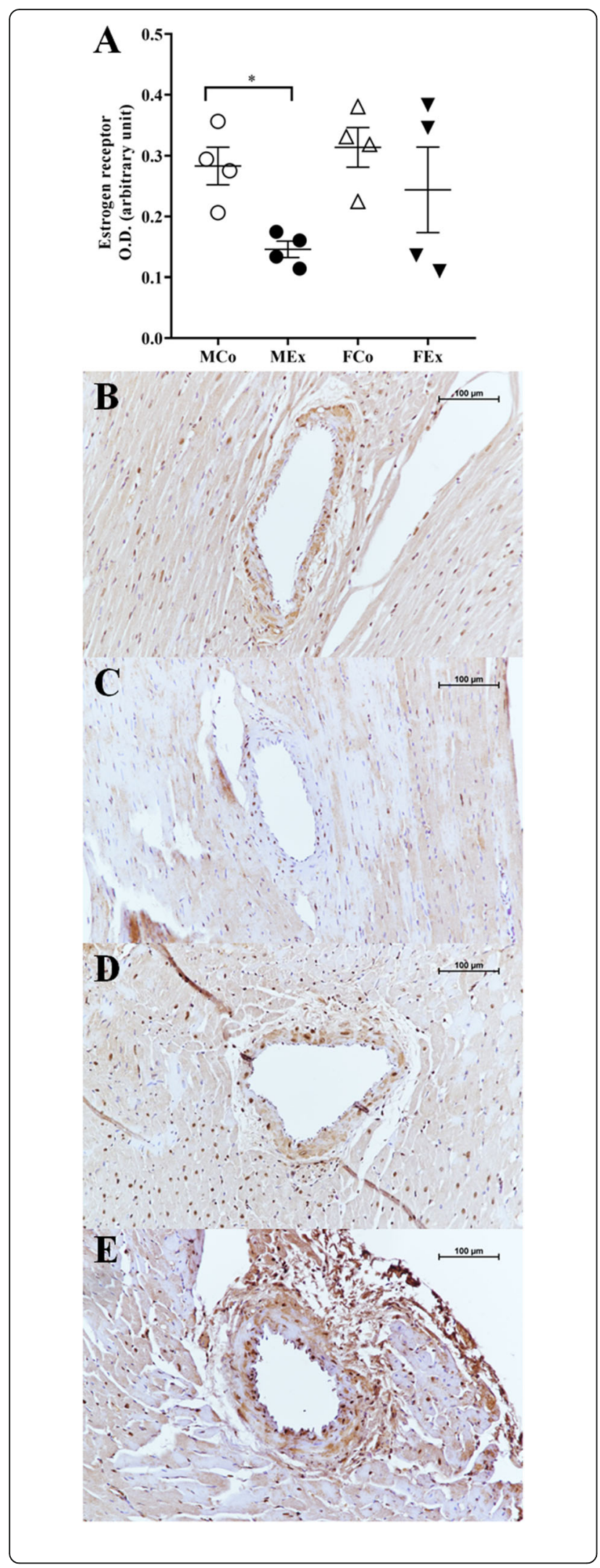

Fig. 9 Results of estrogen receptor (ER) immunohistochemical staining. a ER optical density $(n=4-4-4-4)$; b-e representative images of ER stained arteriole segments from MSed, MEx, FSed and FEx groups. Scale bar, $100 \mu \mathrm{m}$. Two-way ANOVA with post hoc Tukey's test. $\left(F_{\text {training }}=6.004, F_{\text {sex }}=2.317, F_{\text {int }}=0.633, \mathrm{df}_{\text {training }}=1\right.$, $\mathrm{df}_{\text {sex }}=1, \mathrm{df}_{\text {int }}=1, P_{\text {training }}=0.031, P_{\text {sex }}=0.154$ and $\left.P_{\text {int }}=0.442\right)$

exercise, the newly appearing population of 200- to 250$\mu \mathrm{m}$ vessels appeared at not the 'right' place, far from the orifice, though at a distance of $5-8 \mathrm{~mm}$, destroying the hemodynamically advantageous oblique pattern.

\section{Sex differences found}

As described above, we found substantial sex differences in the coronary network in the control groups and in the swim-trained animals. The effect of this strenuous training was also different for the two sexes. The exercise load we applied was similar for males and females. Nevertheless, in females, the elevation of body mass practically ceased, and the improvement of ventricular function was more moderate than in the case of males. Increased muscularity (wall thickness) of the coronary vessels was missing; in effect, there was a thinning of the walls of larger vessels. The remodelling of the network seemed to be less advantageous than in exercised males.

There are substantial differences in the coronary epidemiology between men and women, especially before female menopause $[64,65]$, when the reduction in estrogen levels has a disadvantageous cardiovascular effect $[66,67]$. The mechanism of this needs further explanation. Estrogen $ß$ receptor (ERß) stimulation increased coronary angiogenesis even in male mice suffering from heart failure [43], and a loss of ERß activity increased coronary risk [43, 68-72]. Estrogen stimulates angiogenesis in several tissues through increasing the expression of VEGF, bFGF and eNOS [43, 73, 74] and improves endothelial dilation $[44,75,76]$.

\section{Immunohistochemical examinations}

The imbalance between oxidative and nitrative stress, and antioxidant protection damages cells and tissues at many points. In many conditions and diseases, this balance is significantly disturbed and shifted in the direction of oxidative stress. All of these are the causes or aggravating factors of various diseases, such as inflammatory conditions, cardiovascular diseases or cancerous lesions [77]. Regular physical exercise generally reduces chronic oxidative stress [30]. In our present work, with regards to the degree of oxidative and nitrative stress we found no difference between males and females, or between trained and control groups. This may be explained by the fact that the mechanisms responsible for antioxidant protection may become more prominent as a result of long-term training [30, 78]. 
Interestingly, we found no difference in the staining of VEGFR-1. It has been previously reported in the literature that VEGF mRNA levels increase in striated muscle and myocardium as a result of exercise [39]. However, the literature data on VEGF are not consistent; Kraus et al. found that although acute training increases VEGF in trained men, long-term training does not change circulating VEGF levels at rest [79], there was no difference between trained and untrained, or between men and women with respect to circulating VEGF levels [79, 80]. The opposite results may be due to the fact that VEGF may play a role in angiogenesis at the beginning of training, but is not involved in the maintenance of capillary network during long-term exercise [81].

According to the results of adenosine $\mathrm{A}_{2 \mathrm{~A}}$ receptor staining, we found that training in males reduced the intensity of staining compared with both control males and trained females. Adenosine $\mathrm{A}_{2 \mathrm{~A}}$ receptor expression is increased in hypoxic and ischemic conditions [82, 83]. This fact, and the fact that in our swim-trained animals, on the contrary, the receptor intensity decreased suggests that long-term training improved the myocardial oxygen supply in males.

In our research, we examined the intensity of estrogen receptors by immunohistochemical methods. As a result of training, the intensity of estrogen receptor staining decreased in males.

The potential clinical significance of network pattern for sport adaptation is that geometry of the resistance artery network determines whether the blood supply ventricular tissue follows homogenous pattern, and increased metabolic needs all part of the tissue is properly supplied with oxygenised blood.

\section{Perspectives and significance}

We have provided the first targeted analysis of the longterm exercise adaptation of the resistance-sized coronary artery network geometry as it depends on sex. Wall thickness increases in males. The number of 400- and 200- $\mu \mathrm{m}$ units increased in males, while in females, narrowing of larger $(350 \mu \mathrm{m})$ vessels and appearing of a new rich, 200-250$\mu \mathrm{m}$ population close to the orifice, were characteristic.

\section{Conclusions}

Our experiments have proven that, parallel with improvements in ventricular function, substantial remodelling of the coronary resistance artery network geometry occurs in the hearts of rats subjected to a strenuous, lasting swim exercise programme. There is a substantial sex difference in this process: in males, wall thickness increases, with a morphological dilation of vessels, increasing the numbers of $400-$ and $200-\mu \mathrm{m}$ units, while in females, a narrowing of larger $(350 \mu \mathrm{m})$ vessels and the appearance of a new, rich, 200- to $250-\mu \mathrm{m}$ population close to the orifice are characteristic.

\section{Abbreviations}

$A_{\text {de }} A_{2 A}$ : Adenosine $A_{2 A}$ receptor; $A W T d$ : Anterior wall thickness in diastole; EF: Ejection fraction; eNOS: Endothelial nitric oxide synthase; ER: Estrogen receptor; FEx: Female exercised; FS: Fractional shortening; FSed: Female sedentary; HNE: 4-Hydroxy-2-nonenal; LAD: Left anterior descending; LV: Left ventricle; LVEDD: LV end-diastolic diameter; LVESD: LV end-systolic diameter; MEx: Male exercised; MSed: Male sedentary; nKR: Normal Krebs-Ringer solution; NT: 3-Nitrotyrosine; PAR: Poly(ADP)-ribose; PWTd: Posterior wall thickness in diastole; VEGFR-1: Vascular endothelial growth factor receptor 1

\section{Acknowledgements}

The expert technical assistance of Henriett Biró, Tímea Fischinger, Dóra Juhász, Gábor Fritz, Csaba Mátyás, Éva Pál and Ildikó Oravecz is gratefully acknowledged.

\section{Authors' contributions}

MT: Formal analysis, Investigation, Resources, Data curation, Writing —original draft, Writing - review \& editing, Visualization, Validation, Project administration, Funding acquisition. PM: Formal analysis, Investigation, Data curation, Writing —original draft, Writing—review \& editing. AM-K: Investigation, Data curation, Writing — review \& editing. EMH: Investigation, Formal analysis, Data curation, Writing — review \& editing. RES: Investigation, Data curation, Visualization, Writing — review \& editing. BP: Investigation, Data curation, Visualization, Writing — review \& editing. AJ: Investigation, Data curation, Writing — review \& editing. AAS: Investigation, Data curation, Writing - review \& editing. AO: Formal analysis, Investigation, Data curation, Writing - review \& editing. TR: Conceptualization, Methodology, Validation, Writing - review \& editing, Funding acquisition. BM: Conceptualization, Methodology, Validation, Writing-review \& editing, Funding acquisition. NÁ: Conceptualization, Methodology, Validation, Writing — review \& editing. NG: Formal analysis, Data curation, Investigation, Conceptualization, Methodology, Validation, Writing-review \& editing, Funding acquisition. SV: Conceptualization, Methodology, Validation, Writing-review \& editing, Funding acquisition. The author(s) read and approved the final manuscript.

\section{Funding}

This work was supported by a grant from the National Research, Development and Innovation Office (NKFIH) of Hungary (K120277, K135076, K32019). Project no. NVKP_16-1-2016-0017 ('National Heart Program') has been implemented with the support provided from the National Research, Development and Innovation Fund of Hungary, financed under the NVKP_16 funding scheme. The research was financed by the Thematic Excellence Programme (2020-4.1.1.-TKP2020) of the Ministry for Innovation and Technology in Hungary, within the framework of the Therapeutic Development and Bioimaging thematic programmes of the Semmelweis University. This project was also supported by a grant from the National Development Agency of Hungary (TÁMOP-4.2.2/B-10/1-2010-0013), by the Semmelweis Science and Innovation Fund (STIA-KF-17 for S.V.). Further support has been provided by the Hungarian Hypertension Society and the Dean of the Medical Faculty, Semmelweis University (to Sz.V. and Gy.N.) and by the Semmelweis University (EFOP-3.6.3-VEKOP-16-2017-00009 to M.T.).

\section{Availability of data and materials}

All data generated or analysed during this study are included in this published article (and its supplementary information files).

\section{Declarations}

\section{Ethics approval and consent to participate}

Experimental plans were approved by the Animal Care Committee of Semmelweis University and Hungarian authorities (Permission Number: PEl/ 001/2374-4/2015). Throughout the experiments, all animals received care in compliance with the Principles of Laboratory Animal Care formulated by the National Society for Medical Research and the regulations of the 'Guide for the Care and Use of Laboratory Animals' by the National Institutes of Health (NIH Publication No. 86-23, revised 1996.) and the EU Directive 2010/63/EU were followed.

Consent for publication

Not applicable 


\section{Competing interests}

The authors declare that they have no conflict of interest, financial or otherwise. The authors declare no competing interests.

\section{Author details}

'Department of Obstetrics and Gynecology, Semmelweis University, Üllói u. 78/a, Budapest 1082, Hungary. Institute of Clinical Experimental Research, Semmelweis University, Túzoltó u. 37-47, Budapest 1094, Hungary. ${ }^{3}$ Department of Physiology, Semmelweis University, Túzoltó u. 37-47, Budapest 1094, Hungary. ${ }^{4}$ Department of Neurosurgery, Military Hospital, Róbert Károly körút 44, Budapest 1134, Hungary. ${ }^{5}$ Heart and Vascular Center, Semmelweis University, Városmajor u. 68, Budapest 1122, Hungary.

Received: 8 January 2021 Accepted: 4 May 2021

\section{Published online: 26 May 2021}

\section{References}

1. Neglia D, Liga R, Caselli C, Carpeggiani C, Lorenzoni V, Sicari R, et al. Anatomical and functional coronary imaging to predict long-term outcome in patients with suspected coronary artery disease: the EVINCl-outcome study. Eur Heart J Cardiovasc Imaging 2020;21(11):1273-82. https://doi.org/1 0.1093/ehjci/jez248.

2. Yang TP, Pohost GM. Magnetic resonance coronary angiography. Am Heart Hosp J. 2003;1(2):141-8, 63. https://doi.org/10.1111/j.1541-9215.2003.02089.x.

3. Liga R, Vontobel J, Rovai D, Marinelli M, Caselli C, Pietila M, et al. Multicentre multi-device hybrid imaging study of coronary artery disease: results from the EValuation of INtegrated Cardiac Imaging for the Detection and Characterization of Ischaemic Heart Disease (EVINCI) hybrid imaging population. Eur Heart J Cardiovasc Imaging. 2016;17(9):951-60. https://doi. org/10.1093/ehjci/jew038.

4. Garcia-Canadilla P, de Vries T, Gonzalez-Tendero A, Bonnin A, Gratacos E, Crispi $F$, et al. Structural coronary artery remodelling in the rabbit fetus as a result of intrauterine growth restriction. PLoS One. 2019;14(6):e0218192. https://doi.org/10.1371/journal.pone.0218192.

5. Mittal TK, Pottle A, Nicol E, Barbir M, Ariff B, Mirsadraee S, et al. Prevalence of obstructive coronary artery disease and prognosis in patients with stable symptoms and a zero-coronary calcium score. Eur Heart J Cardiovasc Imaging. 2017;18(8):922-9. https://doi.org/10.1093/ehjci/jex037.

6. Monori-Kiss A, Antal P, Szekeres M, Varbiro S, Fees A, Szekacs B, et al. Morphological remodeling of the intramural coronary resistance artery network geometry in chronically Angiotensin II infused hypertensive female rats. Heliyon. 2020;6(4):e03807. https://doi.org/10.1016/j.heliyon.2020.e03807.

7. Wappler EA, Antal P, Varbiro S, Szekacs B, Simon A, Nagy Z, et al. Network remodeling of intramural coronary resistance arteries in the aged rat: a statistical analysis of geometry. Mech Ageing Dev. 2013;134(7-8):307-13. https://doi.org/10.1016/j.mad.2013.03.002.

8. Tomanek RJ, Aydelotte MR, Butters CA. Late-onset renal hypertension in old rats alters myocardial microvessels. Am J Physiol. 1990;259(6 Pt 2):H1681-7. https://doi.org/10.1152/ajpheart.1990.259.6.H1681.

9. Anversa P, Li P, Sonnenblick EH, Olivetti G. Effects of aging on quantitative structural properties of coronary vasculature and microvasculature in rats. Am J Physiol. 1994;267(3 Pt 2):H1062-73. https://doi.org/10.1152/ajpheart.1 994.267.3.H1062.

10. Lahtinen M, Toukola T, Junttila MJ, Piira OP, Lepojarvi S, Kaariainen M, et al. Effect of changes in physical activity on risk for cardiac death in patients with coronary artery disease. Am J Cardiol. 2018;121(2):143-8. https://doi. org/10.1016/j.amjcard.2017.10.002.

11. Parsons C, Agasthi P, Mookadam F, Arsanjani R. Reversal of coronary atherosclerosis: Role of life style and medical management. Trends Cardiovasc Med. 2018;28(8):524-31. https://doi.org/10.1016/j.tcm.2018.05.002.

12. Mury P, Chirico EN, Mura M, Millon A, Canet-Soulas E, Pialoux V. Oxidative stress and inflammation, key targets of atherosclerotic plaque progression and vulnerability: potential impact of physical activity. Sports Med (Auckland, NZ). 2018;48(12):2725-41.

13. Duncker DJ, Bache RJ. Regulation of coronary blood flow during exercise. Physiol Rev. 2008;88(3):1009-86. https://doi.org/10.1152/physrev. 00045.2006

14. Fernandes T, Barretti DL, Phillips MI, Menezes OE. Exercise training prevents obesity-associated disorders: role of miRNA-208a and MED13. Mol Cell Endocrinol. 2018;476:148-54. https://doi.org/10.1016/j.mce.2018.05.004.
15. Laughlin MH, Bowles DK, Duncker DJ. The coronary circulation in exercise training. Am J Physiol Heart Circ Physiol. 2012;302(1):H10-23. https://doi. org/10.1152/ajpheart.00574.2011.

16. Szekeres M, Nadasy GL, Dornyei G, Szenasi A, Koller A. Remodeling of wall mechanics and the myogenic mechanism of rat intramural coronary arterioles in response to a short-term daily exercise program: role of endothelial factors. J Vasc Res. 2018;55(2):87-97. https://doi.org/10.1159/000486571.

17. Matrai M, Mericli M, Nadasy GL, Szekeres M, Varbiro S, Banhidy F, et al. Gender differences in biomechanical properties of intramural coronary resistance arteries of rats, an in vitro microarteriographic study. J Biomech. 2007;40(5):1024-30. https://doi.org/10.1016/j.jbiomech.2006.04.002.

18. Green DJ, Hopman MT, Padilla J, Laughlin MH, Thijssen DH. Vascular adaptation to exercise in humans: role of hemodynamic stimuli. Physiol Rev. 2017;97(2):495-528. https://doi.org/10.1152/physrev.00014.2016.

19. Heaps CL, Sturek M, Rapps JA, Laughlin MH, Parker JL. Exercise training restores adenosine-induced relaxation in coronary arteries distal to chronic occlusion. Am J Physiol Heart Circ Physiol. 2000;278(6):H1984-92. https://doi. org/10.1152/ajpheart.2000.278.6.H1984.

20. Delaney LE, Arce-Esquivel AA, Kuroki K, Laughlin MH. Exercise training improves vasoreactivity in the knee artery. Int J Sports Med. 2012;33(2):11422. https://doi.org/10.1055/s-0031-1291186.

21. Laughlin $\mathrm{MH}$, Oltman $\mathrm{CL}$, Bowles DK. Exercise training-induced adaptations in the coronary circulation. Med Sci Sports Exerc. 1998;30(3):352-60. https:// doi.org/10.1097/00005768-199803000-00004.

22. Hwang IC, Kim KH, Choi WS, Kim HJ, Im MS, Kim YJ, et al. Impact of acute exercise on brachial artery flow-mediated dilatation in young healthy people. Cardiovasc Ultrasound. 2012;10(1):39. https://doi.org/10.1186/1476-7120-10-39.

23. Pahkala K, Heinonen OJ, Lagstrom H, Hakala P, Simell O, Viikari JS, et al. Vascular endothelial function and leisure-time physical activity in adolescents. Circulation. 2008;118(23):2353-9. https://doi.org/10.1161/ CIRCULATIONAHA.108.791988.

24. Pierce GL, Eskurza I, Walker AE, Fay TN, Seals DR. Sex-specific effects of habitual aerobic exercise on brachial artery flow-mediated dilation in middle-aged and older adults. Clin Sci (London, England: 1979). 2011; 120(1):13-23.

25. Torok M, Monori-Kiss A, Pal E, Horvath E, Josvai A, Merkely P, et al. Longterm exercise results in morphological and biomechanical changes in coronary resistance arterioles in male and female rats. Biol Sex Differ. 2020; 11(1):7. https://doi.org/10.1186/s13293-020-0284-0.

26. Kibel A, Lukinac AM, Dambic V, Juric I, Relatic KS. Oxidative stress in ischemic heart disease. Oxidative Med Cell Longev. 2020;2020:6627144.

27. Milanesi E, Manda G, Dobre M, Codrici E, Neagoe IV, Popescu BO, et al. Distinctive under-expression profile of inflammatory and redox genes in the blood of elderly patients with cardiovascular disease. J Inflamm Res. 2021; 14:429-42. https://doi.org/10.2147/JIR.S280328.

28. Mesquita PHC, Lamb DA, Godwin JS, Osburn SC, Ruple BA, Moore JH, et al. Effects of resistance training on the redox status of skeletal muscle in older adults. Antioxidants (Basel). 2021;10(3):350.

29. Thirupathi A, Wang M, Lin JK, Fekete G, István B, Baker JS, et al. Effect of different exercise modalities on oxidative stress: a systematic review. Biomed Res Int. 2021:2021:1947928.

30. Pingitore A, Lima GP, Mastorci F, Quinones A, lervasi G, Vassalle C. Exercise and oxidative stress: potential effects of antioxidant dietary strategies in sports. Nutrition. 2015;31(7-8):916-22. https://doi.org/10.1016/j.nut.2015.02.005.

31. Castro JP, Jung T, Grune T, Siems W. 4-Hydroxynonenal (HNE) modified proteins in metabolic diseases. Free Radic Biol Med. 2017;111:309-15. https://doi.org/10.1016/j.freeradbiomed.2016.10.497.

32. Horváth EM, Magenheim R, Kugler E, Vácz G, Szigethy A, Lévárdi F, et al. Nitrative stress and poly(ADP-ribose) polymerase activation in healthy and gestational diabetic pregnancies. Diabetologia. 2009;52(9):1935-43. https:// doi.org/10.1007/s00125-009-1435-3.

33. Tóth-Zsámboki E, Horváth E, Vargova K, Pankotai E, Murthy K, Zsengellér $Z$, et al. Activation of poly(ADP-ribose) polymerase by myocardial ischemia and coronary reperfusion in human circulating leukocytes. Mol Med. 2006;12(9-10):221-8. https://doi.org/10.2119/2006-00055.Toth-Zsa mboki.

34. Ahsan H. 3-Nitrotyrosine: a biomarker of nitrogen free radical species modified proteins in systemic autoimmunogenic conditions. Hum Immunol. 2013;74(10):1392-9. https://doi.org/10.1016/j.humimm.2013.06.009.

35. Duncan MW. A review of approaches to the analysis of 3-nitrotyrosine. Amino Acids. 2003;25(3-4):351-61. https://doi.org/10.1007/s00726-003-0022-z. 
36. Xia N, Förstermann U, Li H. Effects of resveratrol on eNOS in the endothelium and the perivascular adipose tissue. Ann N Y Acad Sci. 2017; 1403(1):132-41. https://doi.org/10.1111/nyas.13397.

37. Dong $Y$, Sun $Q$, Liu T, Wang $H$, Jiao $K, X u$ J, et al. Nitrative stress participates in endothelial progenitor cell injury in hyperhomocysteinemia. PLoS One. 2016;11(7):e0158672. https://doi.org/10.1371/journal.pone.0158672.

38. Paganelli F, Gaudry M, Ruf J, Guieu R. Recent advances in the role of the adenosinergic system in coronary artery disease. Cardiovasc Res. 2021; 117(5):1284-94. https://doi.org/10.1093/cvr/cvaa275.

39. Olver TD, Ferguson BS, Laughlin MH. Molecular mechanisms for exercise training-induced changes in vascular structure and function: skeletal muscle, cardiac muscle, and the brain. Prog Mol Biol Transl Sci. 2015;135:227-57. https://doi.org/10.1016/bs.pmbts.2015.07.017.

40. Calvert JW, Condit ME, Aragón JP, Nicholson CK, Moody BF, Hood RL, et al. Exercise protects against myocardial ischemia-reperfusion injury via stimulation of $\beta$ (3)-adrenergic receptors and increased nitric oxide signaling: role of nitrite and nitrosothiols. Circ Res. 2011;108(12):1448-58. https://doi. org/10.1161/CIRCRESAHA.111.241117.

41. Farah C, Kleindienst A, Bolea G, Meyer G, Gayrard S, Geny B, et al. Exerciseinduced cardioprotection: a role for eNOS uncoupling and NO metabolites. Basic Res Cardiol. 2013;108(6):389. https://doi.org/10.1007/s00395-013-03 89-2.

42. Farah C, Nascimento A, Bolea G, Meyer G, Gayrard S, Lacampagne A, et al. Key role of endothelium in the eNOS-dependent cardioprotection with exercise training. J Mol Cell Cardiol. 2017;102:26-30. https://doi.org/10.1016/ j.yjmcc.2016.11.008.

43. Iorga A, Umar S, Ruffenach G, Aryan L, Li J, Sharma S, et al. Estrogen rescues heart failure through estrogen receptor Beta activation. Biol Sex Differ. 2018; 9(1):48. https://doi.org/10.1186/s13293-018-0206-6.

44. Mathews L, lantorno M, Schar M, Bonanno G, Gerstenblith G, Weiss RG, et al. Coronary endothelial function is better in healthy premenopausal women than in healthy older postmenopausal women and men. PLoS One. 2017; 12(10):e0186448. https://doi.org/10.1371/journal.pone.0186448.

45. Radovits T, Olah A, Lux A, Nemeth BT, Hidi L, Birtalan E, et al. Rat model of exercise-induced cardiac hypertrophy: hemodynamic characterization using left ventricular pressure-volume analysis. Am J Physiol Heart Circ Physiol. 2013;305(1):H124-34. https://doi.org/10.1152/a jpheart.00108.2013.

46. Kovacs A, Olah A, Lux A, Matyas C, Nemeth BT, Kellermayer D, et al. Strain and strain rate by speckle-tracking echocardiography correlate with pressure-volume loop-derived contractility indices in a rat model of athlete's heart. Am J Physiol Heart Circ Physiol. 2015;308(7):H743-8. https://doi.org/1 0.1152/ajpheart.00828.2014

47. Teichholz LE, Kreulen T, Herman MV, Gorlin R. Problems in echocardiographic volume determinations: echocardiographic-angiographic correlations in the presence of absence of asynergy. Am J Cardiol. 1976; 37(1):7-11. https://doi.org/10.1016/0002-9149(76)90491-4.

48. Nadasy GL, Szekeres M, Dezsi L, Varbiro S, Szekacs B, Monos E. Preparation of intramural small coronary artery and arteriole segments and resistance artery networks from the rat heart for microarteriography and for in situ perfusion video mapping. Microvasc Res. 2001;61(3):282-6. https://doi.org/1 0.1006/mvre.2000.2297.

49. Dworatzek E, Mahmoodzadeh S, Schubert C, Westphal C, Leber J, Kusch A et al. Sex differences in exercise-induced physiological myocardial hypertrophy are modulated by oestrogen receptor beta. Cardiovasc Res. 2014;102(3):418-28. https://doi.org/10.1093/cvr/cvu065.

50. Olah A, Matyas C, Kellermayer D, Ruppert M, Barta BA, Sayour AA, et al. Sex differences in morphological and functional aspects of exercise-induced cardiac hypertrophy in a rat model. Front Physiol. 2019;10:889. https://doi. org/10.3389/fphys.2019.00889.

51. Olah A, Kovacs A, Lux A, Tokodi M, Braun S, Lakatos BK, et al. Characterization of the dynamic changes in left ventricular morphology and function induced by exercise training and detraining. Int J Cardiol. 2019;277: 178-85. https://doi.org/10.1016/j.ijcard.2018.10.092.

52. Lewicka-Potocka Z, Dabrowska-Kugacka A, Lewicka E, Kaleta AM, Dorniak K, Danilowicz-Szymanowicz L, et al. The "athlete's heart" features in amateur male marathon runners. Cardiol J. 2020. https://doi. org/10.5603/CJ.a2019.0110.

53. Finocchiaro G, Dhutia H, D'Silva A, Malhotra A, Steriotis A, Millar L, et al. Effect of sex and sporting discipline on LV adaptation to exercise. J Am Coll Cardiol Img. 2017;10(9):965-72. https://doi.org/10.1016/j.jcmg.2016.08.011.
54. Konhilas JP, Maass AH, Luckey SW, Stauffer BL, Olson EN, Leinwand LA. Sex modifies exercise and cardiac adaptation in mice. Am J Physiol Heart Circ Physiol. 2004;287(6):H2768-76. https://doi.org/10.1152/ajpheart.00292.2004.

55. Foryst-Ludwig A, Kreissl MC, Sprang C, Thalke B, Bohm C, Benz V, et al. Sex differences in physiological cardiac hypertrophy are associated with exercise-mediated changes in energy substrate availability. Am J Physiol Heart Circ Physiol. 2011;301(1):H115-22. https://doi.org/10.1152/ajpheart. 01222.2010.

56. Murray CD. The physiological principle of minimum work: I. The vascular system and the cost of blood volume. Proc Natl Acad Sci U S A. 1926;12(3): 207-14. https://doi.org/10.1073/pnas.12.3.207.

57. Green DJ, Spence A, Rowley N, Thijssen DH, Naylor LH. Vascular adaptation in athletes: is there an 'athlete's artery'? Exp Physiol. 2012;97(3):295-304. https://doi.org/10.1113/expphysiol.2011.058826.

58. Thijssen DH, Dawson EA, van den Munckhof IC, Birk GK, Timothy Cable N, Green DJ. Local and systemic effects of leg cycling training on arterial wall thickness in healthy humans. Atherosclerosis. 2013;229(2):282-6. https://doi. org/10.1016/j.atherosclerosis.2013.05.013.

59. Ellison GM, Waring CD, Vicinanza C, Torella D. Physiological cardiac remodelling in response to endurance exercise training: cellular and molecular mechanisms. Heart. 2012;98(1):5-10. https://doi.org/10.1136/heartjnl-2011-300639.

60. Verboven M, Cuypers A, Deluyker D, Lambrichts I, Eijnde BO, Hansen D, et al. High intensity training improves cardiac function in healthy rats. Sci Rep. 2019;9(1):5612. https://doi.org/10.1038/s41598-019-42023-1.

61. Li Y, Cai M, Cao L, Qin X, Zheng T, Xu X, et al. Endurance exercise accelerates myocardial tissue oxygenation recovery and reduces ischemia reperfusion injury in mice. PLoS One. 2014;9(12):e114205. https://doi.org/1 0.1371/journal.pone.0114205.

62. Garza MA, Wason EA, Zhang JQ. Cardiac remodeling and physical training post myocardial infarction. World J Cardiol. 2015;7(2):52-64. https://doi.org/1 0.4330/wjc.v7.i2.52.

63. Ardakanizade $M$. The effects of mid- and long-term endurance exercise on heart angiogenesis and oxidative stress. Iran J Basic Med Sci. 2018;21(8):8005. https://doi.org/10.22038/IJBMS.2018.27211.6814.

64. Agarwala A, Michos ED, Samad Z, Ballantyne CM, Virani SS. The use of sexspecific factors in the assessment of women's cardiovascular risk. Circulation. 2020;141(7):592-9. https:/doi.org/10.1161/CIRCULATIONAHA.119.043429.

65. Brown JC, Gerhardt TE, Kwon E. Risk factors for coronary artery disease. StatPearls. Treasure Island: StatPearls Publishing StatPearls Publishing LLC; 2020.

66. Newson L. Menopause and cardiovascular disease. Post Reprod Health. 2018;24(1):44-9. https://doi.org/10.1177/2053369117749675.

67. Schreinlechner M, Noflatscher M, Reinstadler SJ, Sommer P, Lener D, Reiser $E$, et al. Early onset of menopause is associated with increased peripheral atherosclerotic plaque volume and progression. Atherosclerosis. 2020;297: 25-31. https://doi.org/10.1016/j.atherosclerosis.2020.01.023.

68. Umar S, lorga A, Matori H, Nadadur RD, Li J, Maltese F, et al. Estrogen rescues preexisting severe pulmonary hypertension in rats. Am J Respir Crit Care Med. 2011;184(6):715-23. https://doi.org/10.1164/rccm.201101-00780C.

69. Nikolic I, Liu D, Bell JA, Collins J, Steenbergen C, Murphy E. Treatment with an estrogen receptor-beta-selective agonist is cardioprotective. J Mol Cell Cardiol. 2007:42(4):769-80. https://doi.org/10.1016/j.yjmcc.2007.01.014.

70. Pedram A, Razandi M, O'Mahony F, Lubahn D, Levin ER. Estrogen receptorbeta prevents cardiac fibrosis. Mol Endocrinol (Baltimore, Md). 2010;24(11): 2152-65.

71. Wang M, Crisostomo PR, Markel T, Wang Y, Lillemoe KD, Meldrum DR. Estrogen receptor beta mediates acute myocardial protection following ischemia. Surgery. 2008;144(2):233-8. https://doi.org/10.1016/j.surg.2008.03.009.

72. Pelzer T, Loza PA, Hu K, Bayer B, Dienesch C, Calvillo L, et al. Increased mortality and aggravation of heart failure in estrogen receptor-beta knockout mice after myocardial infarction. Circulation. 2005;111(12):1492-8. https://doi.org/10.1161/01.CIR.0000159262.18512.46.

73. Shiojima I, Sato K, Izumiya Y, Schiekofer S, Ito M, Liao R, et al. Disruption of coordinated cardiac hypertrophy and angiogenesis contributes to the transition to heart failure. J Clin Invest. 2005;115(8):2108-18. https://doi.org/10.1172/JCI24682.

74. Elkin M, Orgel A, Kleinman HK. An angiogenic switch in breast cancer involves estrogen and soluble vascular endothelial growth factor receptor 1. J Natl Cancer Inst. 2004;96(11):875-8. https://doi.org/10.1093/ jnci/djh140.

75. Regitz-Zagrosek V, Kararigas G. Mechanistic pathways of sex differences in cardiovascular disease. Physiol Rev. 2017:97(1):1-37. https://doi.org/10.1152/ physrev.00021.2015 
76. Colafella KMM, Denton KM. Sex-specific differences in hypertension and associated cardiovascular disease. Nat Rev Nephrol. 2018;14(3):185-201. https://doi.org/10.1038/nrneph.2017.189.

77. Sabbatino F, Conti V, Liguori L, Polcaro G, Corbi G, Manzo V, et al. Molecules and mechanisms to overcome oxidative stress inducing cardiovascular disease in cancer patients. Life (Basel). 2021;11(2):105.

78. Huang YC, Cheng ML, Tang HY, Huang CY, Chen KM, Wang JS. Eccentric cycling training improves erythrocyte antioxidant and oxygen releasing capacity associated with enhanced anaerobic glycolysis and intracellular acidosis. Antioxidants (Basel). 2021;10(2):285.

79. Kraus RM, Stallings HW 3rd, Yeager RC, Gavin TP. Circulating plasma VEGF response to exercise in sedentary and endurance-trained men. J Appl Physiol (Bethesda, Md : 1985). 2004;96(4):1445-50.

80. Brenner DR, Ruan Y, Adams SC, Courneya KS, Friedenreich CM. The impact of exercise on growth factors (VEGF and FGF2): results from a 12-month randomized intervention trial. Eur Rev Aging Phys Act. 2019;16(1):8. https:// doi.org/10.1186/s11556-019-0215-4.

81. Amaral SL, Sanchez LS, Chang AJ, Rossoni LV, Michelini LC. Time course of training-induced microcirculatory changes and of vegf expression in skeletal muscles of spontaneously hypertensive female rats. Braz J Med Biol Res. 2008;41(5):424-31. https://doi.org/10.1590/50100-879X2008000500012.

82. Grenz A, Homann D, Eltzschig HK. Extracellular adenosine: a safety signal that dampens hypoxia-induced inflammation during ischemia. Antioxid Redox Signal. 2011;15(8):2221-34. https://doi.org/10.1089/ars.2010.3665.

83. von Versen-Höynck F, Rajakumar A, Bainbridge SA, Gallaher MJ, Roberts JM, Powers RW. Human placental adenosine receptor expression is elevated in preeclampsia and hypoxia increases expression of the A2A receptor. Placenta. 2009;30(5):434-42. https://doi.org/10.1016/j.placenta.2009.02.004.

\section{Publisher's Note}

Springer Nature remains neutral with regard to jurisdictional claims in published maps and institutional affiliations.

Ready to submit your research? Choose BMC and benefit from:

- fast, convenient online submission

- thorough peer review by experienced researchers in your field

- rapid publication on acceptance

- support for research data, including large and complex data types

- gold Open Access which fosters wider collaboration and increased citations

- maximum visibility for your research: over $100 \mathrm{M}$ website views per year

At $\mathrm{BMC}$, research is always in progress.

Learn more biomedcentral.com/submissions 